\title{
VIEWS OF WOMEN WITH DISSOCIATIVE IDENTITY DISORDER ON INTIMATE PARTNER VIOLENCE: A GROUNDED THEORY APPROACH
}

\author{
A Dissertation \\ presented to \\ the Faculty of the Graduate School \\ at the University of Missouri-Columbia \\ In Partial Fulfillment \\ of the Requirements for the Degree \\ Doctor of Philosophy \\ by \\ BRIANA L. SNYDER \\ Dr. Deborah Finfgeld-Connett, Dissertation Supervisor \\ MAY 2017
}


The undersigned, appointed by the dean of the Graduate School, have examined the dissertation entitled

VIEWS OF WOMEN WITH DISSOCIATIVE IDENTITY DISORDER ON INTIMATE PARTNER VIOLENCE: A GROUNDED THEORY APPROACH

presented by Briana L. Snyder, a candidate for the degree of doctor of philosophy of nursing, and hereby certify that, in their opinion, it is worthy of acceptance.

Professor Deborah Finfgeld-Connett

Associate Professor Tina Bloom

Associate Professor Maithe Enriquez

Professor Kim Anderson 
Words cannot express how grateful I am for my husband, children, parents, friends, and other loved ones. Without your unwavering support, guidance, and confidence in me, this journey simply would not have been possible. I could write a book about how wonderful each one of you are to me... and maybe one day I will. Thank you to Violet and Oscar for providing the kind of unconditional love and comfort that only elderly dogs can. And thank you to the kind stranger who paid for my coffee the one day I really wanted to give up and quit this whole academic endeavor. I'm still paying it forward.

Thank you. 


\section{ACKNOWLEDGEMENTS}

I would like to thank Dr. Deborah Finfgeld-Connett for being a steadfast voice of reason and patient guide from the very first day of my doctoral career. Thank you for your support and wise advice, and thank you for reinforcing my love for qualitative research. Thank you, Dr. Tina Bloom, for sharing your time, wisdom, and abundant expertise so generously, with such impeccable timing, and with such a compassionate and good-humored tone. I would like to thank Dr. Maithe Enriquez for sharing valuable insights from personal research endeavors with vulnerable populations and for unwavering positivity and optimism. Thank you, Dr. Kim Anderson, for the wealth of experience with intimate partner violence and qualitative methods that you shared to greatly enrich this project, especially while transitioning to a new institution. Each of my committee members was enormously helpful and critical to my success as a doctoral student. Thank you for being such dedicated and selfless mentors.

I would also like to express my gratitude to Dr. Deidre Wipke-Tevis and Dean Judith Fitzgerald Miller. The warm and welcoming atmosphere you create was the main reason I chose to pursue my doctoral degree at Mizzou in the first place. Thank you for always creating new opportunities, being the first to celebrate our successes, and being the first to help us problem-solve our setbacks. Likewise, a gigantic thank you to all of the faculty and staff in the Sinclair School of Nursing - I consider myself extremely lucky to have learned from such a talented, inspirational, and brilliant group of people over the past four years. I am also very fortunate to have spent my doctoral career with a tremendously caring and collaborative cohort of fellow students and friends. It was a blessing to be in the trenches together. 
I remain exceptionally grateful to Dr. Richard Loewenstein and Dr. Bethany Brand for fostering my growth as a psychiatric nurse, scholar, and researcher. Thank you for patiently sharing decades of experience and a wealth of knowledge. I am beyond fortunate to have world-renowned trauma experts as mentors and colleagues.

Additionally, I would like to thank the University of Missouri-Columbia, the Sinclair School of Nursing, the Jonas Center for Nursing and Veterans Healthcare, the International Society for the Study of Trauma and Dissociation, Sheppard Pratt Hospital System, Towson University, and the Maryland Higher Education Commission. Without their financial and institutional support, this endeavor would not have been possible.

Most importantly, I would like to express my most sincere gratitude to the courageous and resilient women who took the time to share stories about some of the most intimate and painful experiences in their lives. You are truly inspirational, and you are the primary reason I have chosen this path. Thank you. 


\section{TABLE OF CONTENTS}

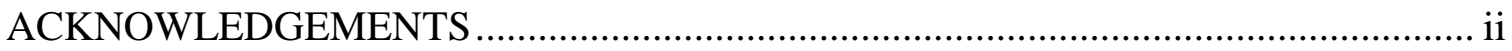

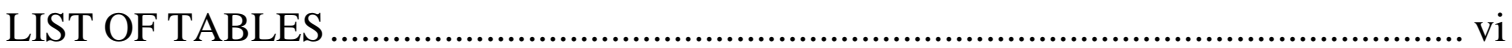

\section{Chapter}

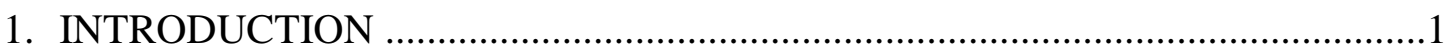

Specific Aims \& Research Questions ........................................................

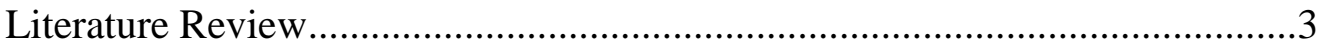

Conceptual Framework ..........................................................................

Research Design \& Methods ..............................................................

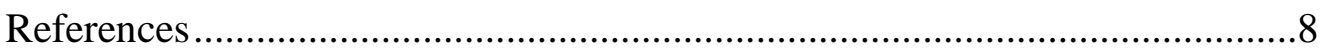

2. CHILD MALTREATMENT AND THE LINK TO EXPERIENCING INTIMATE

PARTNER VIOLENCE IN ADULTHOOD ..............................................11

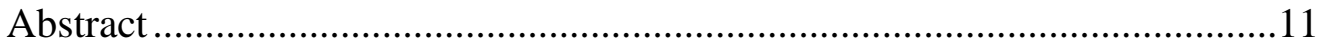

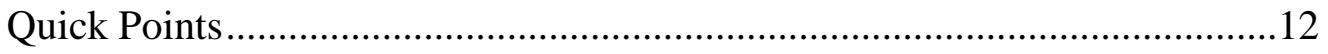

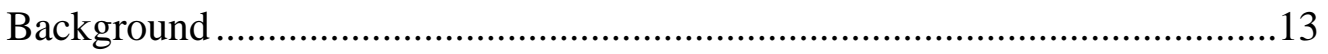

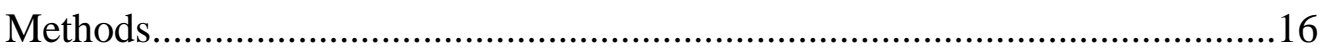

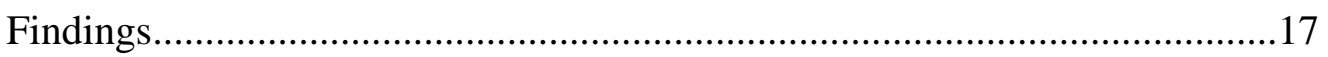

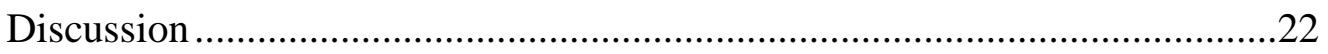

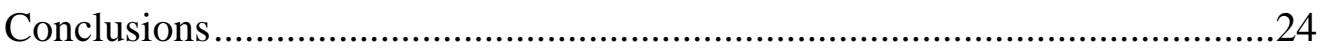

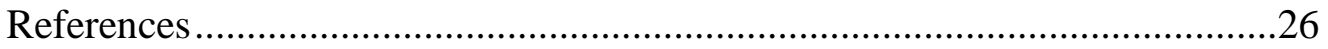

3. WOMEN'S EXPERIENCE OF BEING INTERVIEWED ABOUT ABUSE: A

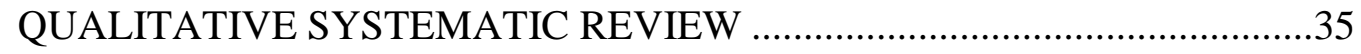

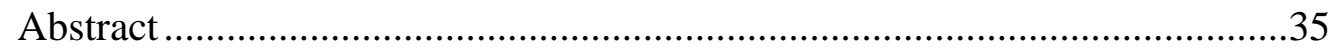

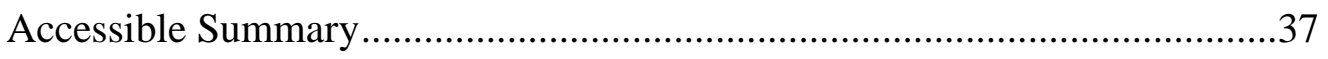

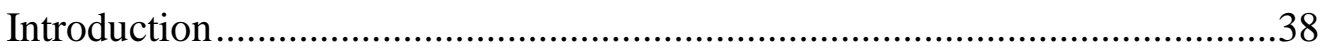

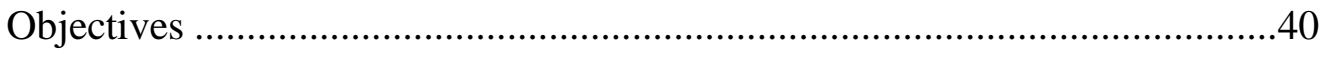




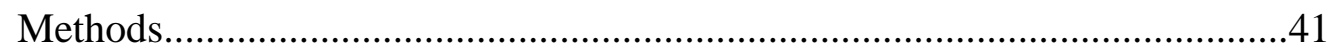

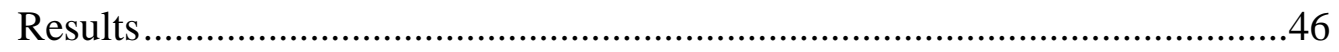

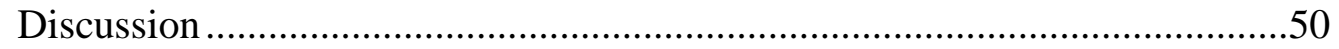

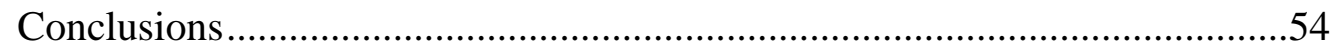

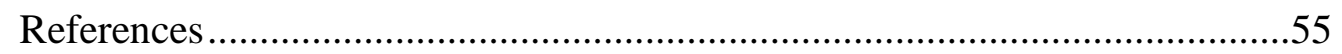

4. WOMEN WITH DISSOCIATIVE IDENTITY DISORDER WHO EXPERIENCE

INTIMATE PARTNER VIOLENCE ........................................................61

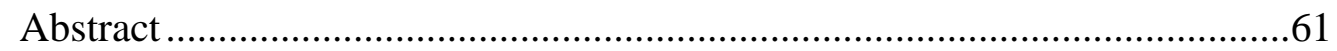

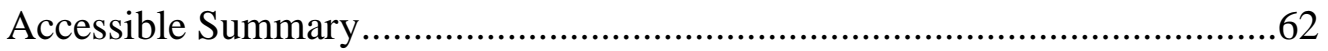

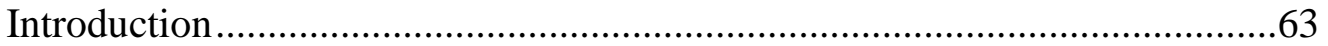

Aim \& Research Questions..................................................................64

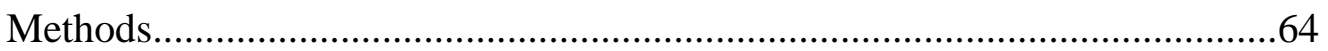

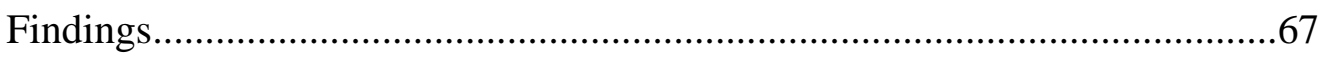

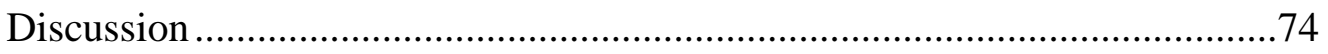

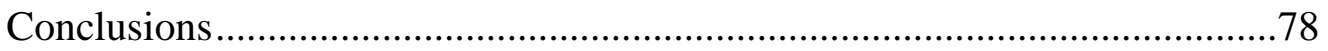

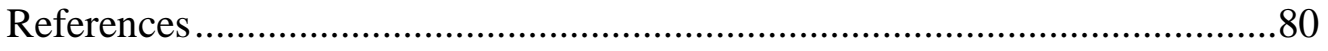

5. CROSS-CHAPTER SUMMARY: CONCLUSIONS AND IMPLICATIONS FOR

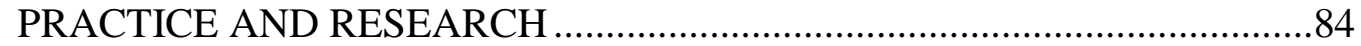

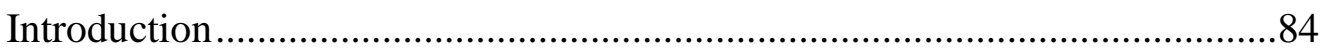

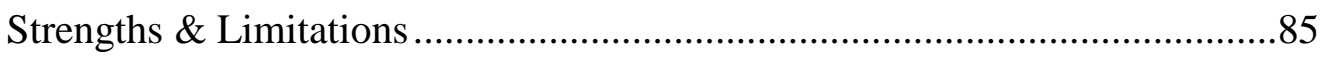

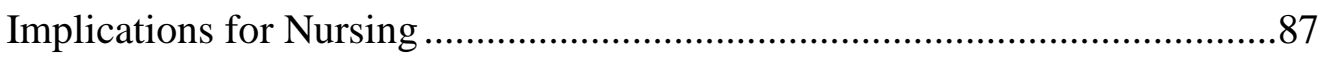

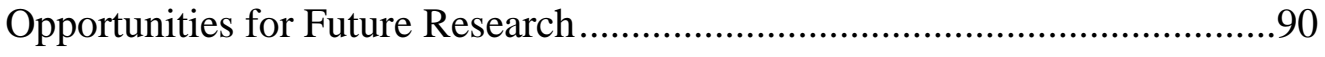

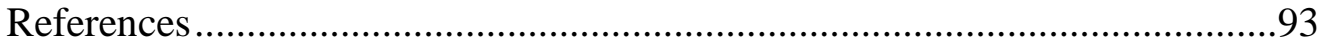

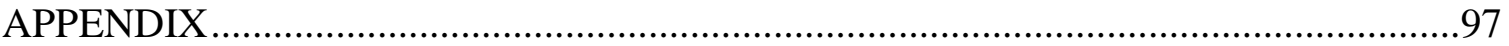

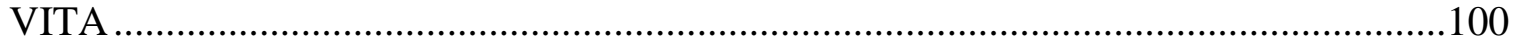




\section{LIST OF TABLES}

Table

Page

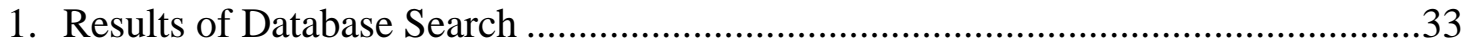

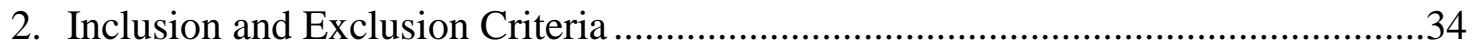

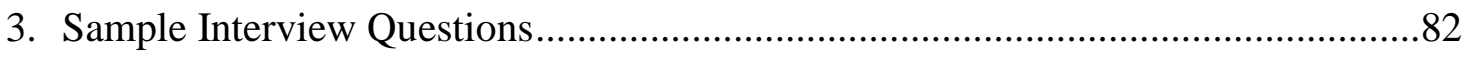

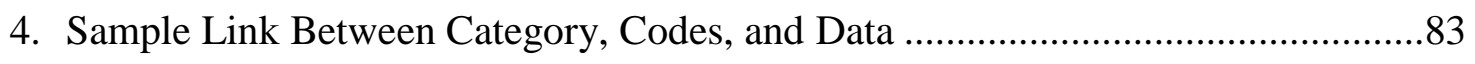




\section{CHAPTER ONE \\ INTRODUCTION}

A diagnosis of dissociative identity disorder (DID) can result from severe and sustained abuse and neglect in childhood that begins at a very young age (American Psychiatric Association [APA], 2013). It is estimated that a diagnosis of DID affects about one percent of the population (over three million Americans), making DID as common as schizophrenia (Brand, Loewenstein, \& Lanius, 2014).

All forms of child maltreatment are well documented risk factors for exposure to intimate partner violence (IPV) in adulthood, which can lead to exacerbated mental health problems, increased incidence of psychiatric hospitalization, and increased suicidality (Laylor \& McElvaney, 2010). It is estimated that one in four women will experience IPV at some point in her lifetime. In the United States (U.S.), over 200,000 women are raped by an intimate partner each year, and approximately 1.3 million women are physically assaulted by an intimate partner each year (Black et al., 2011).

Very little research has focused on the overlap of DID and IPV. Women with DID present with unique challenges related to IPV, due to forgetting abuse, underreporting abuse, suffering from an impaired ability to detect danger and self-protect, and other factors. Some personality states may love the abuser, some may hate the abuser, and some may be indifferent or unaware of the abuse. Therefore, our current understanding of the experience of women with DID who experience IPV may not be accurate or sufficient. This is particularly concerning because it is estimated that the IPV rate for survivors of childhood maltreatment is at least double that of the general population (Arnow, 2004; Webermann, Brand, \& Chasson, 2014). 


\section{Specific Aims and Research Questions}

Primary Specific Aim: Inform the development of a theory that explicates the coping experiences of women with DID who have experienced IPV.

Secondary Aim: Describe the experiences of women with DID and the factors that contribute to their continued engagement in abusive relationships in adulthood.

Research Question 1: How do women with DID cope with IPV?

Research Question 2: What are the experiences of women with DID who are exposed to IPV, and what factors contribute to continued exposure to IPV?

\section{Literature Review}

\section{Child Maltreatment}

Child abuse and neglect are highly prevalent and serious problems that experts believe are grossly underreported. In 2012 alone, the U.S. Department of Health and Human Services (HHS) reported that over 3.2 million children were the subject of at least one Child Protective Services (CPS) report of child maltreatment, and 686,000 children were confirmed survivors of abuse and neglect (about 9.2 per 1,000 children). An estimated 1,640 children died as a result of abuse and neglect in 2012 (HHS). Along with a plethora of other physical, psychological, emotional, and behavioral disturbances, a diagnosis of DID can result from severe and sustained maltreatment throughout childhood (APA, 2013).

\section{Dissociative Identity Disorder (DID)}

DID is the most serious and chronic of the dissociative disorders, causing severe impairment in functioning that frequently requires inpatient psychiatric hospitalization to prevent catastrophic self-harm and suicide (Brand et al., 2014). Studies indicate that the 
prevalence of dissociative disorders in the general population is about ten percent (APA, 2013). Women are at a higher risk for developing DID and dissociative disorders in general because they are more likely to experience abuse and violence than men (Brand et al., 2014; World Health Organization [WHO], 2016).

DID is characterized by the presence of two or more distinct personality states that repeatedly take control of an individual, causing changes in behavior, significant lapses in memory, alterations in consciousness, changes in affect, and impairment in judgment, perception, and cognition (APA, 2013). A host personality state usually identifies with the individual's legal name and may be unaware of the presence of some or all alternate personality states. Different personality states typically remember different aspects of autobiographical information, resulting in significant amnesia that goes beyond normal forgetfulness (APA, 2013; Brand et al., 2014). Environmental events, particularly stressors like IPV, can cause rapid shifts between personality states and severely impaired functioning. As a result, women with DID may be more vulnerable to IPV, less likely to acknowledge or seek help for IPV, or may not go through the same coping process as other IPV survivors.

\section{Intimate Partner Violence (IPV)}

IPV, also referred to as domestic violence and spousal abuse, includes any physical, sexual, emotional, psychological, spiritual, and financial abuse, aggression, or coercion by a current or former intimate partner, which also includes stalking and dating violence (Centers for Disease Control and Prevention [CDC], 2015). Intimate partners can be current and former spouses, boyfriends, girlfriends, and sexual partners. IPV occurs in both heterosexual and non-heterosexual relationships and does not require 
sexual intimacy (CDC, 2015). Like DID, IPV disproportionately affects women, with roughly 85 percent of survivors being female (Black et al., 2011). Like child maltreatment, IPV is another underreported phenomenon with enormously tragic personal and societal consequences. Survivors endure tremendous pain and suffering, which can result in earlier death and decreased quality of life due to physical, psychological, and emotional problems. Children of IPV survivors are more likely to have physical, psychological, emotional, and behavioral problems that result in missing school, dropping out of school, and increased juvenile and adult crime rates. Girls who witness IPV are more likely to experience IPV as adults, and boys who witness IPV are more likely to become abusers than their non-abused counterparts (Song, Wenzel, Kim, \& Nam, 2015).

From a financial standpoint, the most recent data from 1995 indicates that IPV in the U.S. costs nearly $\$ 6$ billion each year, about $\$ 4$ billion of which is related to medical and mental health services, even though less than one-fifth of survivors seek care (National Center for Injury Prevention and Control [NCIPC], 2003). IPV results in over 18.5 million mental healthcare visits each year. Female survivors of IPV lose over 8 million hours of paid work each year, the equivalent of over 32,000 full-time jobs. Women who experience IPV are more likely to attempt and die by suicide, and nearly one-third of female homicide victims are killed by an intimate partner, highlighting the seriousness of this issue (NCIPC, 2003).

\section{Conceptual Framework}

Freyd (1994) first proposed the concept of betrayal trauma in the early 1990s, which is defined as a violation of trust that produces a conflict as a result of both an 
individual's innate desire to avoid future betrayals and dependence on a caregiver necessary for survival. Child maltreatment, in any form, is a prime example of betrayal trauma, especially when the abuser is a primary caregiver. From a survival standpoint, the abused child is best served by behaving in a way that will not worsen the caregiver's abuse or neglect, such as pretending the abuse is not occurring rather than fighting back. Freyd (1994) developed betrayal trauma theory (BTT) to address and describe this need for survivors to develop dissociative amnesia, remaining unaware of the abuse in order to survive.

BTT provided a sound framework for this research study involving females experiencing IPV who are diagnosed with DID because it addressed the unique dissociative aspect of these women's experiences as an adaptive survival mechanism resulting from child maltreatment. BTT also accounted for the need to maintain a relationship with an abusive partner on whom the women may be dependent for housing, food, finances, and other necessities (Freyd, 1994). Since women diagnosed with DID are survivors of child maltreatment, BTT was applicable in that these women may have already adaptively developed dissociative amnesia as a result of child maltreatment and may continue to use it in current abusive situations. Survivors of IPV are frequently terrorized by abusive partners with threats of serious harm to self and loved ones if abuse is disclosed, as are child maltreatment survivors, and this may intensify fears and contribute to dissociative amnesia (Barnes, Noll, Putnam, \& Trickett, 2009).

Additionally, BTT explicated another barrier to interrupting the cycle of IPV, given that abused women may be victims of betrayal blindness, in which IPV is ignored because it is considered to be normal, tolerable, or shameful (Platt, Barton, \& Freyd, 2009). In this 
study, BTT was used to develop interview questions. It was also used to examine the findings.

\section{Research Design and Methods}

A grounded theory approach was used to describe the experiences of women with DID who are survivors of IPV and their coping strategies. The purpose of grounded theory is to gain understanding of the ways in which reality is socially constructed, with the eventual goal of theory development (Richards \& Morse, 2013). A grounded theory approach is warranted when studying phenomena in which change occurs, seeking to understand and describe the process by which that change occurs by learning from participants. The researcher analyzes data in the form of interviews, field notes, and observations, while looking for emerging concepts that may generate theoretical insight and lead to the development of a midrange theory (Richards \& Morse, 2013). Grounded theory was an appropriate method for this investigation because the study aimed to describe the coping process of women diagnosed with DID who experience IPV. 


\section{References}

American Psychiatric Association. (2013). Diagnostic and statistical manual of mental disorders $\left(5^{\text {th }}\right.$ ed.). Washington, DC: American Psychiatric Publishing.

Arnow, B.A. (2004). Relationships between childhood maltreatment, adult health and psychiatric outcomes, and medical utilization. Journal of Clinical Psychiatry, 65. Retrieved from http://www.ncbi.nlm.nih.gov/pubmed/15315472

Barnes, J., Noll, J., Putnam, F., \& Trickett, P. (2009). Sexual and physical revictimization among victims of severe childhood sexual abuse. Child Abuse \& Neglect, 33, 412-410. doi:10.1016/j.chiabu.2008.09.013

Black, M.C., Basile, K.C., Breiding, M.J., Smith, S.G., Walters, M.L., Merrick, M.T., Chen, J., \& Stevens, M.R. (2011). The national intimate partner and sexual violence survey (NISVS): 2010 summary report. Atlanta, GA: National Center for Injury Prevention and Control, Centers for Disease Control and Prevention. Retrieved from https://www.cdc.gov/violenceprevention/pdf/nisvs_report2010a.pdf

Brand, B.L., Loewenstein, R.J., \& Lanius, R.A. (2014). Dissociative identity disorder. In G. Gabbard (Ed.), Gabbard's Treatments of Psychiatric Disorders (pp. 439-458). Washington, D.C.: American Psychiatric Publishing.

Centers for Disease Control and Prevention, (2015). Intimate partner violence surveillance: Uniform definitions and recommended data elements. Retrieved from https://www.cdc.gov/violenceprevention/pdf/intimatepartnerviolence.pdf

Freyd, J.J. (1994). Betrayal trauma: Traumatic amnesia as an adaptive response to childhood abuse. Ethics \& Behavior, 4, 307-329. 
Laylor, K., \& McElvaney, R. (2010). Child sexual abuse, links to later sexual exploitation/high-risk sexual behavior, and prevention/treatment programs. Trauma, Violence, \& Abuse, 11, 159-177. doi: 10.1177/1524838010378299

National Center for Injury Prevention and Control. (2003). Costs of intimate partner violence against women in the United States. Atlanta, GA: Centers for Disease Control and Prevention. Retrieved from https://www.cdc.gov/violenceprevention/pdf/IPVBook-a.pdf

Platt, M., Barton, J., \& Freyd, J.J. (2009). A betrayal trauma perspective on domestic violence. In E. Stark \& E. S. Buzawa (Eds.), Violence against women in families and relationships (pp. 185-207). Westport, CT: Greenwood Press.

Richards, L., \& Morse, J. (2013). Readme first for a user's guide to qualitative methods. Los Angeles, CA: SAGE.

Song, A., Wenzel, S.L., Kim, J.Y., \& Nam, B. (2015). Experience of domestic violence during childhood, intimate partner violence, and the deterrent effect of awareness of legal consequences. Journal of Interpersonal Violence, 32, 357-372. doi: $10.1177 / 0886260515586359$

United States Department of Health and Human Services, Administration for Children and Families, Administration on Children, Youth and Families, Children's Bureau. (2012). Child maltreatment 2012. Retrieved from http://www.acf.hhs.gov/programs/cb/research-data-technology/statisticsresearch/child-maltreatment 
Webermann, A.R., Brand, B.L., \& Chasson, G.S. (2014). Childhood maltreatment and intimate partner violence in dissociative disorder patients. European Journal of Psychotraumatology, 5, 1-8. doi: 10.3402/ejpt.v5.24568

World Health Organization. (2016). Violence against women. Retrieved from http://www.who.int/mediacentre/factsheets/fs239/en/ 


\title{
CHAPTER TWO
}

\section{CHILD MALTREATMENT AND THE LINK TO EXPERIENCING INTIMATE PARTNER VIOLENCE IN ADULTHOOD}

This invited manuscript is currently under review at the Journal of Midwifery \& Women's Health.

\begin{abstract}
Abuse and neglect are global phenomena with devastating personal, familial, and societal effects. When occurring in childhood, maltreatment increases the risk for additional abuse experiences across the lifespan. This purpose of this review is to summarize and analyze current research about the relationship between the experience of child maltreatment (CM) and intimate partner violence (IPV) in adulthood. The majority of literature supports that $\mathrm{CM}$ increases the risk for IPV, and the link appears to be stronger in specific populations, including female veterans, teens, sexual minorities, and individuals with mental illness. Nurse-midwives are uniquely poised to prevent and address this maltreatment, due to the intimate nature of the care they provide to clients and their families, but continue to encounter barriers in practice. Nurse-midwives need additional resources and training related to abuse, and they must take an active role in assessing, treating, providing resources, and making appropriate referrals to interprofessional colleagues.
\end{abstract}

Keywords: child abuse, child maltreatment, intimate partner violence, domestic violence, spousal abuse 


\section{Quick Points}

- Abuse and neglect, including child maltreatment and intimate partner violence, are serious problems worldwide.

- A history of child maltreatment increases the risk for experiencing intimate partner violence in adulthood.

- Nurse-midwives are uniquely poised to play a key role in preventing and addressing abuse and neglect, due to the intimate nature of the care they provide to women and their families.

- Nurse-midwives must thoroughly assess all clients for abuse and neglect, particularly those with a history of child maltreatment.

Abuse and neglect are complex phenomena that affect millions of individuals worldwide in all stages of life (World Health Organization [WHO], 2016a). In addition to the tragic personal consequences of abuse and neglect, the profound negative effects on families, communities, and society as a whole are pervasive and sustained over time. Despite concerted prevention and intervention efforts, these multifaceted problems continue to be a major cause for concern, demanding attention and action from key institutions, such as the World Health Organization (WHO), United Nations (UN), Centers for Disease Control and Prevention (CDC), and the Health and Medicine Division of the National Academies (formerly the Institute of Medicine, or IOM). Although complicated in nature and difficult to study, extensive research has been conducted on the topics of abuse and neglect, particularly on the cumulative effects of multiple occurrences across the lifespan. This review examines the current literature on 
abuse and neglect, specifically the link between child maltreatment (CM) and intimate partner violence (IPV) in adulthood.

CM and IPV can cause serious harm to an individual's physical and mental health, with potential culmination in death, homicide, and suicide (Centers for Disease Control and Prevention [CDC], 2016; WHO, 2016a). Nurses, again ranked as the most trusted profession in the United States (US) for the $15^{\text {th }}$ straight year (Gallup, 2016), are uniquely poised to play a significant role in preventing and addressing this abuse and neglect (Snyder, 2016; WHO, 2016a). Nurse midwives are no exception, particularly due to the intimate nature of the care they provide to women and their families (Mauri, Nespoli, Persico, \& Zobbi, 2015). Implications for nurse midwifery practice, areas warranting additional research, and suggested courses of action regarding CM and IPV are discussed at the conclusion of this review.

\section{Background}

\section{Child Maltreatment}

Child maltreatment (CM), also referred to as child abuse and neglect, is defined as "all forms of physical and emotional ill-treatment, sexual abuse, neglect, and exploitation that results in actual or potential harm to the child's health, development, or dignity" (WHO, 2016a). CM applies to individuals under the age of 18 years old and encompasses physical abuse, sexual abuse, emotional abuse, psychological abuse, neglect, and witnessed abuse, such as intimate partner violence (IPV; Gay, Harding, Jackson, Burns, \& Baker, 2013; Iverson, McLaughlin, Adair, \& Monson, 2014; Snyder, 2016; WHO, 2016a; Widom, Czaja, \& Dutton, 2014). In general, experts agree that CM is underreported for a variety of reasons: varying definitions of $\mathrm{CM}$, failure to report due 
to shame or cultural norms, failed detection by mandated reporters, misclassification of $\mathrm{CM}$ as accidental, and poor reporting or tracking practices by various local or national organizations (CDC, 2016; WHO, 2016a). This inconsistency can result in wide ranges in $\mathrm{CM}$ estimates, adding to difficulties in $\mathrm{CM}$ research. Still, global estimates indicate that about 1 in 5 women and 1 in 13 men experience sexual abuse as a child (WHO, 2016a). About $25 \%$ of all adults report experiencing physical abuse as a child (WHO, 2016a). Children are especially susceptible to maltreatment in war zones and refugee settings, but CM is perpetrated most commonly by someone known to the child (WHO, 2016a; CDC, 2016).

In the US, the Department of Health and Human Services reported that over 3.2 million children were the subject of at least one Child Protective Services (CPS) report of $\mathrm{CM}$, and 686,000 children were confirmed to have experienced abuse and neglect (about 9.2 per 1,000 children) in 2012 alone (CDC, 2014). In estimated 1,640 American children died as a result of CM in 2012 (CDC, 2014). According to the most recent data, groups experiencing the highest rates of $\mathrm{CM}$ are those under the age of 1 year, females, and African Americans (CDC, 2014). In the US, the overwhelming majority (80.3\%) of CM perpetrators were parents, followed by other relatives, unmarried partners of parents, acquaintances, and strangers (CDC, 2014). In addition to immeasurable personal suffering and far-reaching effects on families and society, the total lifetime financial cost of fatal and nonfatal CM cases is over \$120 billion in the US (CDC, 2014).

While it is apparent that all forms of CM are traumatic, there is debate among experts as to which form of CM is the most detrimental. Neglect and emotional abuse are cited most frequently as the forms of $\mathrm{CM}$ with the most damaging effects on the survivor, 
which may be a result of the constant, omnipresent nature of these types of abuse (Atmaca \& Gençöz, 2016; Gay et al., 2013; Webermann, Brand, \& Chasson, 2014; Widom et al., 2014). While physical and sexual abuse tend to occur as separate events, children often report that emotional abuse and neglect seem to be continuous and inescapable (Widom et al., 2014). Additionally, emotional abuse may be more insidious and difficult for children to recognize and for outsiders to detect (Gay et al., 2013). Despite a recent increase in recognition of its harmful effects, the literature reflects that the most often overlooked form of CM is witnessing IPV between parents and primary caregivers (Faulkner, Goldstein, \& Wekerle, 2014; Iverson et al., 2014; Webermann et al., 2014).

\section{Intimate Partner Violence}

Intimate partner violence (IPV), also referred to as domestic violence and spousal abuse, is defined as any physical, sexual, emotional, psychological, spiritual, and financial abuse, aggression, or coercion by a current or former intimate partner (CDC, 2015). IPV also includes stalking and dating violence. Just as witnessing IPV is a form of CM, threatened or actual CM by an abusive partner is recognized as a form of emotional and psychological IPV (Zanoni, Warburton, Bussey, \& McMaugh, 2014). Intimate partners can be current and former spouses, boyfriends, girlfriends, and sexual partners. IPV occurs in both heterosexual and homosexual relationships and does not require sexual intimacy (CDC, 2015). IPV can be unidirectional, meaning only one partner is the abuser, or bidirectional (also referred to as mutual or reciprocal IPV) in which both partners are abusive toward each other (Flemke \& Underwood, 2014; Gay et al., 2013; Iverson et al., 2014). 
Like CM, IPV is widespread and underreported, with inestimable tragic consequences (Black et al., 2010; CDC, 2015). About $85 \%$ of those who experience IPV are female, and roughly 1 in 4 American women will experience IPV at some point in her lifetime (CDC, 2015; United States Department of Justice [USDOJ], 2017). IPV rates are slightly higher internationally, with an estimated 1 in 3 women predicted to experience IPV (WHO, 2016b). Over 200,000 American women are raped by an intimate partner each year, and roughly 1.3 million American women are physically abused by an intimate partner each year (USDOJ, 2017). Globally, IPV survivors are more likely to have poor physical and mental health outcomes, and they are more likely to attempt and die by suicide or intimate partner homicide than their non-abused counterparts (Black et al., 2010; WHO, 2016b). From an economic standpoint, IPV costs many nations billions of dollars annually, despite estimates that less than $20 \%$ of IPV survivors seek care (Black et al., 2010; WHO, 2016b). Factors thought to increase the risk of experiencing IPV include low socioeconomic status, low educational level, unemployment, substance abuse, social isolation, mental illness, and others (CDC, 2015). One of the more complex factors implicated in the risk for experiencing IPV as an adult is a history of CM.

\section{Methods}

The question this literature review sought to answer was: what is the link between CM and IPV? Cumulative Index to Nursing and Allied Health Literature (CINAHL), MEDLINE, and PsycINFO were the databases chosen, based upon their relevance to CM and IPV. Searches were performed using combinations of the following terms: child maltreatment, child abuse AND intimate partner violence, domestic violence, spousal abuse. After an initial search of each database, a total of 1,948 articles were retrieved, 
and 260 were deemed suitable for consideration (Table 1). After applying inclusion and exclusion criteria (Table 2) and reading abstracts closely, 28 articles were chosen for inclusion in this review (Table 1). All 28 articles were read carefully, and major findings were extracted and compiled.

\section{The Complex Link}

Though multifaceted and challenging to study, the majority of current scientific research supports the position that a personal history of CM increases an individual's risk for experiencing IPV as an adult (Atmaca \& Gençöz, 2016; Barrios et al., 2015; Iverson et al., 2014; Simmel, Postmus, \& Lee, 2012; Webermann et al., 2014; Widom et al., 2014; Zamir \& Lavee, 2015). Expert opinions and scientific evidence diverge, however, on the exact nature, strength, and comprehensiveness of the link between CM and IPV, with the understanding that the experience of CM alone does not cause future IPV. Some studies demonstrate that all forms of CM increase the odds of experiencing IPV later in life (Anderson, Howard, Dean, Moran, \& Khalifeh, 2016; Barrios et al., 2015; Kaukinen, Buchanan, \& Gover, 2016). Others differentiate between different forms of CM and their link to specific types of IPV, often with contrary results.

In a retrospective study of Turkish women researchers found that sexual and emotional CM specifically predicted physical, psychological, and sexual IPV, while physical CM was only associated with physical IPV in adulthood (Atmaca \& Gençöz, 2016). Conversely, a study of female Jordanian college students demonstrated that physical CM led to a higher risk of physical and sexual IPV in adulthood, while those who had witnessed IPV had a higher risk of severe physical IPV (Al-Modallal, 2016). A study of American college women indicated that emotional CM had a stronger link to all 
forms of IPV than any other type of CM (Gay et al., 2013), while another study conducted with both men and women demonstrated that neglect had the most significant link to IPV (Widom et al., 2014). Other researchers have found that more severe IPV is linked to specific forms of CM: betrayal trauma (CM perpetrated by a trusted primary caregiver on which the child is dependent for survival, usually a parent) (Babcock \& DePrince, 2012; Babcock \& DePrince, 2013), complex trauma (repeated and sustained CM perpetrated by a primary caregiver at key, early developmental junctures) (Flemke \& Underwood, 2014), and double betrayal trauma (betrayal trauma coupled with a negative response to CM disclosure to an authority figure) (Wager, 2013).

In contrast, several scientific studies have failed to find a significant relationship between a personal history of CM and the experience of IPV in adulthood, at least between particular forms of each or under specific conditions (Brown, Burnette, \& Cerulli, 2015; Engstrom, El-Bassel \& Gilbert, 2012; Zamir \& Lavee, 2014). Brown et al. (2015) argue that CM is linked to post-traumatic stress disorder (PTSD) but not necessarily IPV. Findings from their study with a population of American women indicated that the perception of danger may be more important than the number or severity of traumatic childhood events, so it is critical to determine how individuals perceive the impact of CM on their daily lives (Brown et al., 2015). Similar results have been reproduced in a group of American nurses and a population of minority men, indicating that screening for PTSD and post-traumatic stress symptoms (PTSS) may aid in identifying individuals at risk for future IPV (Loeb et al., 2014; Messing, La Flair, Cavanaugh, Kanga, \& Campbell, 2012). Likewise, in a population of female substance abusers, Engstrom, El-Bassel and Gilbert (2012) found that sexual CM involving force 
and perpetrated by family was associated with PTSD and overall psychological distress but not IPV directly. Findings from a study with female Israeli graduate students demonstrated that CM was not significantly associated with IPV when participants had high levels of psychological mindedness, indicating that the ability to effectively selfregulate emotion is a protective factor for survivors (Zamir \& Lavee, 2014). While in a population of female American veterans, researchers found that physical CM was not linked to IPV (Iverson, Mercado, Carpenter, \& Street, 2013). Ultimately, no research study is without flaws, and researchers on all sides of this complex issue acknowledge limitations in their work; however, key institutions and organizations validate that the experience of CM increases the risk for IPV in adulthood, based on the preponderance of scientific evidence (Black et al., 2010; CDC, 2015; CDC, 2016; WHO, 2016a).

\section{Special Populations}

The literature also demonstrates that certain populations of people with a CM history may be more vulnerable to and more likely to experience IPV than others, indicating that $\mathrm{CM}$ does not affect all people equally. For example, several researchers evaluated their findings by gender (Anderson et al., 2016; Kaukinen et al., 2015; Loeb et al., 2014; Zanoni et al., 2014). A study of American men and women showed that the link between CM and sexual IPV was weaker for women than for men (Anderson et al., 2016). A suggested explanation for this finding was that women tend to experience more violence and trauma over the course of their lives than men, so unfortunately, CM may not seem as catastrophic or abnormal for female survivors as it does for males and may not result in the same detrimental, long-term effects (Anderson et al., 2016). In a population of male and female college students, sexual CM and neglect increased the risk 
of bidirectional IPV in males, while physical CM and neglect carried the greatest risk for bidirectional IPV in females (Kaukinen et al., 2015).

Minority gender and sexuality groups experience high rates of CM and IPV, including transgendered, homosexual, and bisexual individuals (Koeppel \& Bouffard, 2014). Koeppel and Bouffard (2014) found that non-heterosexuals with a CM history were more likely to experience IPV than their heterosexual counterparts with a CM history, with bisexual individuals reporting higher rates of abuse than homosexuals. One theory for the higher rate of abuse in this population is due to gender atypicality (the idea that non-heterosexual boys are "sissies" and non-heterosexual girls are "tomboys"), which may worsen abuse for children who do not fit into rigid culturally gender norms (Koeppel \& Bouffard, 2014). In general, gender differences in CM and IPV are challenging to define, as significantly more data exist on the experiences of females than males or other gender populations. While it is commonly accepted that abuse disproportionately affects more women than men, other causes for the dearth of data on male abuse experiences may include limited reporting due to shame, embarrassment, and cultural norms as well as failure of others to believe reports based on the false assumption that males can only be perpetrators of abuse (Loeb et al., 2014; Zanoni et al., 2014).

Race, ethnicity, and culture appear to influence the link between CM and IPV, as well (Atmaca \& Gençöz, 2016; Barrios et al., 2015; Kaukinen et al., 2015; Kennedy, Bybee, Kulkarni, \&Archer, 2012; Loeb et al., 2014). A link between CM and IPV has been demonstrated through research in a variety of cultures worldwide, including those in North America, South America, Asia, Africa, Europe, Australia, and the Middle East, and is recognized by the $\mathrm{WHO}$ and $\mathrm{UN}$ as a global phenomenon (Al-Modallal, 2016; Atmaca 
\& Gençöz, 2016; Chan, 2011; United Nations [UN], 2016; WHO, 2016b). Research indicates that the link between CM and IPV tends to be stronger, particularly for women, in cultures with strict beliefs about gender roles and expectations (Al-Modallal, 2016; CDC, 2015). In a sample of American college students without a history of CM, African American women had a significantly higher rate of bidirectional IPV than Caucasian women (Kaukinen et al., 2015). Findings from the same study showed that CM significantly increased the likelihood of bidirectional IPV for both Caucasian and African American women to almost equal levels; however, African American men were significantly more likely than Caucasian men to experience bidirectional IPV when both had a history of CM (Kaukinen et al., 2015). Socioeconomic status is another factor thought to interact with race and gender related to the link between CM and IPV. Lower socioeconomic status and unemployment are known risk factors for IPV (CDC, 2015) and have been tied to increased rates of IPV in CM survivors, as well (Barrios et al., 2015; Kennedy et al., 2012).

Other populations with unique considerations include veterans, individuals with a substance abuse history, and individuals with mental illness (Anderson et al., 2016; Engstrom et al., 2012; Iverson et al., 2013; Chou, 2012). Female veterans are more likely to experience IPV than nonveteran females, and a history of sexual CM combined with unwanted sexual advances while in the military increase their IPV risk even further (Iverson et al., 2013). In a group of men and women receiving community mental health treatment, all forms of CM independently increased the odds of IPV in adulthood (Anderson et al., 2016). In another study by Chou (2012), adults with mental illness with a history of CM and IPV were significantly more likely to be psychiatrically hospitalized 
and retraumatized. Interestingly in a population of women with a substance abuse history, sexual CM was not associated with IPV, but was significantly associated with PTSD (Engstrom et al., 2012).

\section{Discussion}

\section{Implications for Nurse-Midwives}

So, what does this mean for nurse-midwives? First, knowledge of the risks for and signs of IPV is mandatory for providing comprehensive, holistic care to clients and families (Williams, Foster, \& Watts, 2013). Although IPV does not discriminate, and individuals from all walks of life experience abuse, research indicates that certain groups are more vulnerable than others and warrant increased vigilance and inquiry on the part of the nurse-midwife. Specifically, nurse-midwives should have a higher index of suspicion for IPV when working with clients who have survived CM, as this review demonstrates that the majority of current evidence supports this link.

Second, more comprehensive, focused training on assessment and intervention strategies for clients experiencing IPV must be incorporated into midwifery curricula. When surveyed, most midwifery students report feeling insufficiently prepared to deal with IPV (Bradbury-Jones \& Broadhurst, 2015). Among practicing nurse-midwives, two-thirds did not know the risks for and signs of IPV when surveyed, despite $88 \%$ of them reporting having some kind of IPV training (Baird, Saito, Eustace, \& Creedy, 2015). The literature continues to demonstrate that providers can be resistant to assess for abuse for a variety of reasons, despite clients wanting to be asked about it (BradburyJones \& Taylor, 2013; Bradbury-Jones, Taylor, Kroll, \& Duncan, 2014; Snyder, 2016; Williams et al., 2013). Fortunately, most midwifery students and nurse-midwives report 
a desire for additional knowledge and training regarding IPV, which should include learning to assess for abuse experiences across the lifespan (Baird et al., 2015; BradburyJones \& Broadhurst, 2015). Beyond traditional educational experiences, researchers have found success using platforms like World Café to foster discussion and share knowledge on the topic of IPV (Halsall \& Marks-Maran, 2014).

Third, nurse-midwives must engage in active self-reflection regarding their own attitudes and potential biases about CM and IPV. Due to the pervasive nature of abuse, it is reasonable to assume that nurse-midwives may have experienced abuse themselves or have loved ones who are survivors, which may influence their personal beliefs and treatment of their clients (Bradbury-Jones \& Taylor, 2013). Nurse-midwives must have access to resources for personal and professional support when working with survivors of abuse, due to the potential emotional and psychological burdens associated with their care (Williams et al., 2013).

Along those lines, nurse-midwives rely on their professional organizations, such as the American College of Nurse-Midwives (ACNM), to provide education and clear protocols when working with survivors of abuse, so these institutions must have easily accessible, evidence-based tools and resources available for use in practice (Halsall \& Marks-Maran, 2014; Krans, Moloci, Housey, \& Davis, 2014). Organizations must go beyond merely recommending that nurse-midwives screen all clients for abuse and outline specifically how the assessment should be done and the precise steps for action when abuse is determined to be present. For example, the Abused Women, Awareness, Recognition, and Empowerment (AWARE) framework developed by Bradbury-Jones et al. (2014) can assist nurse-midwives and students with the complex disclosure process by 
both aiding clients in recognizing their experiences as abusive, as well as aiding providers in recognizing and taking action when abuse is present. Other research supports various models and assessments for providers working with survivors of IPV, which should be evaluated for utility based on nurse-midwifery scope and standards of practice (Krans et al., 2014; Williams et al., 2013).

\section{Future Research}

Aside from brief mention in the context of bidirectional IPV, the welldocumented link between CM and perpetration of IPV is beyond the scope of this review. Additional research is warranted involving the responsibilities of nurse-midwives when caring for clients who are perpetrators of IPV. Additionally, recent research has shown that roughly $50 \%$ of nurse-midwives made referrals to outside providers (e.g., social workers, psychiatrists, and psychologists) when clients presented with psychosocial stressors, such as IPV (Krans et al., 2014). This movement towards more integrated and interprofessional care shows promise for increased efficiency, continuity of care, and improved client outcomes (Krans et al., 2014; Messing, Campbell, Wilson, Brown, \& Patchell, 2017; Williams et al., 2013). Further research may elucidate best practices in coordinating care for midwifery clients who are survivors of abuse, as well as optimal ways to incorporate interprofessional collaboration in nurse-midwifery education and training.

\section{Conclusions}

CM and IPV are complex and multifaceted phenomena, as is the link between them. Though anyone may experience abuse, women are at a disproportionate risk. As intimate care providers to women and their families, nurse-midwives must be prepared to 
assess their clients and recognize signs of IPV, particularly those with a CM history. Early detection and intervention are essential to favorable health outcomes for survivors of abuse, so nurse-midwives and other providers must consistently take an active role in addressing this pervasive problem. This involves engaging in continuing education, keeping current with evidence-based best practices, conducting thorough assessments on all clients and their families, documenting appropriately, offering resources, and making referrals to interprofessional colleagues as appropriate. 


\section{References}

Al-Modallal, H. (2016). Child maltreatment in college women: Effect on severe physical partner violence. Journal of Family Violence, 31, 607-615.

Anderson, F., Howard, L., Dean, K., Moran, P., \& Khalifeh, H. (2016). Childhood maltreatment and adulthood domestic violence and sexual violence victimization among people with severe mental illness. Social Psychiatry \& Psychiatric Epidemiology, 51, 961-970.

Atamaca, S., \& Gençöz, T. (2016). Exploring revictimization process among Turkish women: The role of early maladaptive schemas on the link between child abuse and partner violence. Child Abuse \& Neglect, 52, 85-93.

Babcock, R., \& DePrince, A. (2012). Childhood betrayal trauma and self-blame appraisals among survivors of intimate partner abuse. Journal of Trauma \& Dissociation, 13(5), 526-538.

Babcock, R., \& DePrince, A. (2013). Factors contributing to ongoing intimate partner abuse: Childhood betrayal trauma and dependence on one's perpetrator. Journal of Interpersonal Violence, 28(7), 1385-1402.

Baird, K.M., Saito, A.S., Eustace, J., \& Creedy, D.K. (2015). An exploration of Australian midwives' knowledge of intimate partner violence against women during pregnancy. Women \& Birth, 28, 215-220.

Barrios, Y.V., Gelaye, B. Zhong, Q., Nicolaidis, C., Rondon, M.B., Garcia, P.J.,...Williams, M.A. (2015). Association of childhood physical and sexual abuse with intimate partner violence, poor general health and depressive symptoms among pregnant women. PLoS ONE, 10(1). 
Black, M. C., Basile, K. C., Breiding, M. J., Smith, S. G., Walters, M. L., Merrick, M. T., ... Stevens, M. R. (2011). The National Intimate Partner and Sexual Violence Survey (NISVS): 2010 Summary Report. National Center for Injury Prevention and Control, Centers for Disease Control and Prevention. Retrieved from http://www.cdc.gov/violenceprevention/pdf/nisvs_executive_summary-a.pdf

Bradbury-Jones, C., \& Taylor, J. (2013). Domestic abuse as a transgressive practice: Understanding nurses' responses through the lens of abjection. Nursing Philosophy, 14, 295-304.

Bradbury-Jones, C., Taylor, J., Kroll T., \& Duncan, F. (2014). Domestic abuse awareness and recognition among primary healthcare professionals and abused women: A qualitative investigation. Journal of Clinical Nursing, 23, 3057-3068.

Bradbury-Jones, C., \& Broadhurst, K. (2015). Are we failing to prepare nursing and midwifery students to deal with domestic abuse? Findings from a qualitative study. Journal of Advanced Nursing, 71(9), 2062-2072.

Brown, J., Burnette, M.L., \& Cerulli, C. (2015). Correlations between sexual abuse histories, perceived danger, and PTSD among intimate partner violence victims. Journal of Interpersonal Violence, 30(15), 2709-2725.

Centers for Disease Control and Prevention. (2014). Child maltreatment. Retrieved from https://www.cdc.gov/violenceprevention/pdf/childmaltreatment-facts-at-aglance.pdf

Centers for Disease Control and Prevention. (2015). Intimate partner violence surveillance: Uniform definitions and recommended data elements. Retrieved from https://www.cdc.gov/violenceprevention/pdf/intimatepartnerviolence.pdf 
Centers for Disease Control and Prevention. (2016). Injury prevention and control: Division of violence prevention. Retrieved from https://www.cdc.gov/violenceprevention/

Chan, K. (2011). Association between childhood sexual abuse and adult sexual victimization in a representative sample in Hong Kong Chinese. Child Abuse \& Neglect, 35(3), 220-229.

Chou, K. (2012). Childhood sexual abuse and psychiatric disorders in middle-aged and older adults: Evidence from the 2007 Adult Psychiatric Morbidity Survey. Journal of Clinical Psychiatry, 73(11), 1365-1371.

Engstrom, M., El-Bassel, N., \& Gilbert L. (2012). Childhood sexual abuse characteristics, intimate partner violence exposure, and psychological distress among women in methadone treatment. Journal of Substance Abuse Treatment, 43(3), 366-376.

Faulkner, B., Goldstein, A.L., \& Wekerle, C. (2014). Pathways from childhood maltreatment to emerging adulthood investigating trauma-mediated substance use and dating violence outcomes among child protective services-involved youth. Child maltreatment, 19(3-4), 219-232.

Flemke, K., \& Underwood, J. (2014). Childhood abuse and women's use of intimate partner violence: Exploring the role of complex trauma. Partner Abuse, 5(1), 98112.

Gallup. (2016). Americans rate healthcare providers high on honesty, ethics. Retrieved from http://www.gallup.com/poll/200057/americans-rate-healthcare-providershigh-honesty-ethics.aspx 
Gay, L.E., Harding, H.G., Jackson, J.L., Burns, E.E., \& Baker, B.D. (2013). Attachment style and early maladaptive schemas as mediators of the relationship between childhood emotional abuse and intimate partner violence. Journal of Aggression, Maltreatment \& Trauma, 22(4), 408-424.

Halsall, S., \& Marks-Maran, D. (2014). Welcome to my café: Facilitating a domestic abuse workshop for midwives. British Journal of Midwifery, 22(11), 806-812.

Iverson, K.M., McLaughlin, K.A., Adair, K.C., \& Monson, C.M. (2014). Anger-related dysregulation as a factor linking childhood physical abuse and interparental violence to intimate partner violence experiences. Violence \& Victims, 29(4), 564578.

Iverson, K.M., Mercado, R., Carpenter, S.L., \& Street, A.E. (2013). Intimate partner violence among women veterans: Previous interpersonal violence as a risk factor. Journal of Traumatic Stress, 26(6), 767-771.

Kaukinen, C. Buchanan, L., \& Gover, A. (2015). Child abuse and the experience of violence in college dating relationships: Examining the moderating effect of gender and race. Journal of Family Violence, 30, 1079-1092.

Kennedy, A., Bybee, D., Kulkarni, S., \& Archer, G. (2012). Sexual victimization and family violence among urban African American adolescent women: Do violence cluster profiles predict partner violence victimization and sex trade exposure? Violence Against Women, 18(11), 1319-1338.

Koeppel, M.D.H., \& Bouffard, L. (2014). Sexual orientation, child abuse, and intimate partner violence victimization. Violence \& Victims, 29(3), 436-450. 
Krans, E.E., Moloci, N.M., Housey, M.T., \& Davis, M.M. (2014). Impact of psychosocial risk factors on prenatal care delivery: A national provider survey. Maternal \& Child Health Journal, 18, 2362-2370.

Loeb, T.B., Holloway, I.W., Galvan, F.H., Wyatt, G.E., Myers H.F., Glover, D.A.,...Liu, H. (2014). Associations between intimate partner violence and posttraumatic stress symptom severity in a multiethnic sample of men with histories of childhood sexual abuse. Violence \& Victims, 29(3), 451-463.

Mauri, E.M., Nespoli, M., Persico, G., \& Zobbi, V. (2015). Domestic violence during pregnancy: Midwives' experiences. Midwifery, 31(5), 498-504.

Messing, J.T., La Flair, L., Cavanaugh, C.E., Kanga, M.R., \& Campbell, J.C. (2012). Testing posttraumatic stress as a mediator of childhood trauma and adult intimate partner violence victimization. Journal of Aggression, Maltreatment \& Trauma, 21(7), 792-811.

Messing, J.T., Campbell, J.C., Wilson, J.S., Brown, S., \& Patchell, B. (2017). The lethality screen: The predictive validity of an intimate partner violence risk assessment for use by first responders. Journal of Interpersonal Violence, 32(2), 205-226.

Simmel, C., Postmus, J., \& Lee, I. (2012). Sexual revicitimization in adult women: Examining factors associated with their childhood and adulthood experiences. Journal of Child Sexual Abuse, 21(5), 593-611.

Snyder, B. L. (2016). Women's experience of being interviewed about abuse: A qualitative systematic review. Journal of Psychiatric and Mental Health Nursing, 23, 605-613. 
United Nations. (2016). 'The price of no change is unacceptable'- UN and civil society global campaigns aim to end violence against women. Retrieved from http://www.un.org/apps/news/story.asp?NewsID=55775\#.WG_4iYWcFPY

United States Department of Justice. (2013). Intimate partner violence: Attributes of victimization. Retrieved from http://www.bjs.gov/content/pu/pdf/ipvav9311.pdf

Wager, N. (2013). Sexual revictimization: Double betrayal and the risk associated with dissociative amnesia. Journal of Child Sexual Abuse, 22, 878-899.

Webermann, A.R., Brand, B.L., \& Chasson, G.S. (2014). Childhood maltreatment and intimate partner violence in dissociative disorder patients. European Journal of Psychotraumatology, 5, 1-8.

Widom, C.S., Czaja, S., \& Dutton, M.A. (2014). Child abuse and neglect and intimate partner violence victimization and perpetration: A prospective investigation. Child Abuse \& Neglect, 38(4), 650-663.

Williams, H., Foster, D., \& Watts, P. (2013). Perinatal domestic abuse: Midwives making a difference through effective public health practice. British Journal of Midwifery, 21(12), 852-858.

World Health Organization. (2016a). Child maltreatment. Retrieved from http://www.who.int/topics/child_abuse/en/

World Health Organization. (2016b). Violence against women. Retrieved from http://www.who.int/mediacentre/factsheets/fs239/en/

Zamir, O., \& Lavee, Y. (2014). Psychological mindedness as a protective factor against revictimization in intimate relationships. Journal of Clinical Psychology, 70(9), 847-859. 
Zamir, O., \& Lavee, Y. (2015). Emotional awareness and breaking the cycle of revicitmization. Journal of Family Violence, 30(6), 675-684.

Zanoni, L., Warburton, W., Bussey, K., \& McMaugh, A. (2014). Child protection fathers' experiences of childhood, intimate partner violence and parenting. Children and Youth Services Review, 46, 91-102. 
Table 1

Results of Database Search

\begin{tabular}{|l|l|l|l|l|}
\hline \multicolumn{1}{|c|}{ Database } & Number of articles & \multicolumn{1}{c|}{$\begin{array}{c}\text { Number of } \\
\text { duplicates }\end{array}$} & Irrelevant articles & $\begin{array}{c}\text { Number of articles } \\
\text { to be considered }\end{array}$ \\
\hline CINAHL & 731 & 332 & 313 & 85 \\
\hline MEDLINE & 450 & 236 & 102 & 112 \\
\hline PsycINFO & 768 & 378 & 327 & 63 \\
\hline Total & 1,948 & 946 & 742 & 260 \\
\hline \multicolumn{2}{|l}{ Total number of articles included in review after inclusion/exclusion criteria applied } & 28 \\
\hline
\end{tabular}


Table 2

Inclusion and Exclusion Criteria

Inclusion Criteria

- $\quad$ All types of CM and IPV

- National and international populations

- Experimental and non-experimental research reports

- Qualitative, quantitative, and mixed methods designs

- Peer-reviewed articles

- Written in English

- Date limit 2011-2016 to capture most current information
Exclusion Criteria

- Opinion papers, commentaries, and letters to the editor

- Articles focusing on the link between CM and future perpetration of IPV only 


\title{
CHAPTER THREE
}

\section{WOMEN'S EXPERIENCE OF BEING INTERVIEWED ABOUT ABUSE: A QUALITATIVE SYSTEMATIC REVIEW}

Snyder, B.L. (2016). Women's experience of being interviewed about abuse: A qualitative systematic review. Journal of Psychiatric and Mental Health Nursing. 23, 605-613. doi: 10.1111/jpm.12353

\begin{abstract}
Introduction

Collections of quantitative data exist outlining the costs and benefits of asking female research participants about their abuse experiences; however, no known meta-syntheses have been conducted to evaluate the qualitative data that exist on the experiences of women being asked about their abuse.

Aim/Question
\end{abstract}

The purpose of this qualitative systematic review was to analyze and interpret qualitative findings regarding asking women about their abuse experiences with the intention of understanding risks and benefits.

Method

The sample $(\mathrm{N}=11)$ was derived from an expansive search of peer-reviewed literature using multidisciplinary electronic databases. Qualitative findings were extracted, coded, and categorized. Reflective memos were developed, and themes emerged.

Results

While initially distressing, being interviewed about abuse is more beneficial than harmful for women, due to the therapeutic process of talking about abuse. 


\section{Discussion}

To maximize the therapeutic impact of discussing abuse, women must maintain autonomy and feel they are in a safe and confidential environment. Within this supportive atmosphere, very few women report any regret after discussing abuse and are able to identify positive outcomes.

Implications for Practice

Findings from this review support the need for mental health nurses and other clinicians to create an optimal environment for discussing abuse and offer relevant practice recommendations. Researchers are encouraged to include women in studies that involve asking about abuse experiences.

Keywords: abuse, domestic violence, interview, intimate partner violence, qualitative methodology, women survivors of abuse 


\section{Accessible Summary}

\section{What is known on the subject}

- There is disagreement about the costs and benefits of asking women about their abuse experiences in practice and research settings.

- No known meta-syntheses have been conducted to evaluate the qualitative data that exist on the experiences of women being asked about their abuse.

\section{What this paper adds to the existing knowledge}

- This review adds robust qualitative evidence that interviewing women about their abuse experiences can be a beneficial and healing experience for them.

- Mental health nurses are in an ideal position to create a therapeutic environment to interview women about their abuse experiences.

\section{What are the implications for practice}

- Mental health nurses are strongly encouraged to ask about and document abuse in all of their interviews and assessments, as well as act as advocates and discuss reported abuse within their interdisciplinary teams, in order to provide individualized, trauma-informed care.

- The mental health nurse should listen attentively, avoid judgment, offer reassurance, make appropriate referrals, and provide resources for women, including those with both past and current abuse histories.

- Nurses are strongly encouraged to ask about abuse in all settings in which they encounter women, including in psychiatric and mental health settings. 


\section{Introduction}

\section{Rationale}

Abuse is a devastating and widespread societal problem that can take many forms, most commonly physical, sexual, emotional, verbal, and financial in nature (Centers for Disease Control and Prevention, 2016). Abuse can occur at any age and occurs between intimate partners, family members, acquaintances, and strangers (Centers for Disease Control and Prevention, 2016). Although both sexes experience abuse, research has shown that females are more likely to be abused (U.S. Department of Justice, 2013). The impact of abuse is not limited to the experiences of the survivor and extends far beyond to include the survivor's family, community, and society as a whole (Black et al., 2011).

Child abuse and neglect are substantial societal problems that experts believe are grossly underreported. In 2012 alone, the U.S. Department of Health and Human Services reported that over 3.2 million children were the subject of at least one Child Protective Services (CPS) report of child maltreatment, and 686,000 children were confirmed victims of abuse and neglect (about 9.2 per 1,000 children). An estimated 1,640 children died as a result of abuse and neglect in 2012 (U.S. Department of Health and Human Services, 2012). Those that survive abuse and neglect often have poorer health outcomes than the general population and are more likely to remain caught in the cycle of abuse (Black et al., 2011). In fact, all forms of child maltreatment are well documented risk factors for experiencing intimate partner violence (IPV) in adulthood, and subsequently, the focus of this qualitative systematic review (QSR) relates to abuse experienced by women across the lifespan (Laylor \& McElvaney, 2010). 
IPV disproportionately affects women, with roughly $85 \%$ of victims being female (Black et al., 2011). It is estimated that one in four American women will experience IPV at some point in her lifetime (U.S. Department of Justice, 2013). Globally, the rate of IPV increases to one in three women (World Health Organization, 2016). In the U.S., over 200,000 women are raped by an intimate partner each year, and 1.3 million women are physically assaulted by an intimate partner each year (U.S. Department of Justice, 2013). Nearly half of women report suffering psychological aggression by an abuser, and one in six women report experiencing stalking to the extent that they feared for their lives or the lives of their loved ones (Black et al., 2011). Like child maltreatment, IPV is another underreported phenomenon with enormously tragic personal and societal consequences. Survivors endure tremendous pain and suffering, resulting in earlier death and decreased quality of life due to physical, psychological, and emotional problems (Black et al., 2011).

From a financial standpoint, the most recent data from 1995 indicates that IPV in the US costs nearly $\$ 6$ billion each year, about $\$ 4$ billion of which is related to medical and mental health services, even though less than one-fifth of survivors seek care for their injuries. IPV results in over 18.5 million mental health care visits each year. Female survivors of IPV lose over 8 million hours of paid work each year, the equivalent of over 32,000 full-time jobs, as a result of abuse and are less likely to perform household chores and necessary childcare responsibilities (National Center for Injury Prevention and Control, 2003). Australian estimates are similar to those in the US, indicating that IPV costs over $\$ 6.1$ billion ( $\$ 8.1$ billion Australian dollars) each year (Australian Government, 2004). Promising data from the United Kingdom (UK) demonstrate that 
both the rate and financial impact of IPV have decreased from 2001 to 2008; however, the annual cost continues to exceed $\$ 21$ million (£16m) (Walby, 2009). Worldwide, women who experience IPV are more likely to attempt and die by suicide, and roughly one-third of female homicide victims are killed by an intimate partner as reported by law enforcement (National Center for Injury Prevention and Control, 2003; World Health Organization, 2016).

\section{Objectives}

Although the statistics support the obvious need for research and interventions aimed at addressing the problem of abuse, there remain varying opinions on the costs and benefits of asking women about their abuse experiences. Without question, learning about the experiences of these women is invaluable because they offer first-hand accounts, but opinions differ on how to best obtain that information. Researchers have found that some individuals, including healthcare providers, harbor the opinion that asking female patients in healthcare settings and female research participants about sensitive and traumatic topics like abuse will be psychologically and emotionally detrimental to them, causing potentially life-threatening decompensation (Burke Draucker, 1992; Örmon, Sunnqvist, Bahtsevani, \& Torstensson Levander, 2016). On the opposite end of the continuum, others argue that asking women about their abuse experiences is cathartic and aids in the healing process, while failing to ask about abuse experiences is harmful and neglectful (Becker-Blease \& Freyd, 2006; Örmon et al., 2016). This debate is of particular relevance to mental health nurses, as the literature demonstrates that the majority of women treated in mental health settings have experienced at least one form of abuse over their lifetime, with the highest rates of abuse 
reported among psychiatric inpatients (National Center on Domestic Violence, Trauma and Mental Health, 2011; Örmon et al., 2016).

Aim and research questions. Collections of quantitative data exist outlining the costs and benefits of asking female research participants about their abuse experiences; however, no known meta-syntheses have been conducted to evaluate the qualitative data that exists on the experiences of women being asked about their abuse in both healthcare and research settings. Therefore, the purpose of this QSR is to thoroughly analyze and interpret qualitative findings related to asking women about their abuse experiences across the lifespan with the intention of understanding risks and benefits, as well as making recommendations on how to best interview women about abuse in clinical practice and how to best include female survivors of abuse and their experiences in future research endeavors. The aim of this QSR is to address aspects of the following questions: what are women's experiences of being interviewed about abuse? Do they find it beneficial/helpful, and if so, why? Do they find it harmful/unhelpful, and if so, why? How do women prefer to be interviewed about abuse?

\section{Methods}

Qualitative systematic reviews are the result of the methodical collection, analysis, and interpretation of qualitative research findings on a given topic (FinfgeldConnett, 2010). Seasoned researchers use intuitive, creative, and rigorous literature searching techniques, such as berrypicking and footnote chasing, to compile a sample of qualitative studies and analyze the findings from these studies (Bates, 1989). The purpose of conducting QSRs may vary and can include model and theory development, as well as making qualitative research findings more meaningful and accessible to those 
in clinical practice and policy-making arenas (Ring, Ritchie, Mandava, \& Jepson, 2011).

The methods used in conducting this QSR were selected with the intention of synthesizing and building knowledge, rather than simply compiling data on women's experience of being interviewed about abuse.

\section{Search and Information Sources}

An expansive literature search was conducted in the PubMed, Scopus, and Ovid databases. Expansive literature searches identify relevant sources that are rich in data and contribute to data saturation, without being exhaustive and redundant (Finfgeld-Connett \& Johnson, 2013). The idea for this QSR resulted from a quantitatively-focused article on the ethical implications of asking female research participants about past child and intimate partner abuse (Becker-Blease \& Freyd, 2006). The literature review began with a broad, general search using the phrase asking women about abuse, which returned 130 sources in PubMed, 173 sources in Scopus, and 10,990 in Ovid. The purpose of this initial broad search was to investigate if a sufficient number of qualitative studies existed on this topic, as well as to identify keywords and Medical Subject Heading (MeSH) terms that could be used to refine further searches. Sources were excluded if they were quantitative in nature, letters or opinion pieces, written in a language other than English, or focused on elder abuse, substance abuse, and military trauma, as these topics are unique, substantial phenomena that are not within the scope of this QSR. Of the sources returned on the initial search, 41 articles that were qualitative or mixed-methods in nature were identified that were relevant to the topic of this QSR, which indicated it was likely that a meaningful systematic review could be conducted. 
Important keywords and MeSH terms identified as a result of this initial exploration of the literature included abused women, battered women, domestic violence, intimate partner violence, spouse abuse, qualitative, screening, interview, and focus group. Additional searches were conducted using combinations of these keywords and MeSH terms; however, no new sources resulted from these searches. Literature search strategies consistent with Bates' (1989) berrypicking method were employed, including footnote chasing, citation searching, and author searching, in an attempt to achieve the ideal goal of retrieving all studies relevant to women's experience of being interviewed about abuse for analysis and synthesis, rather than a sample of them (Barroso et al., 2003).

In keeping with an expansive approach, literature searches were not limited by date, culture, or country initially but were limited to sources available in English. Ultimately, due to the paucity of qualitative research about women's experience of being interviewed about abuse, no additional restrictions were necessary and, therefore, not imposed. The full text of each of the 41 sources was assessed for eligibility. Sources were excluded for methodological inconsistencies, unclear data collection procedures, and duplicate analyses of the same data set. Of the 41 sources identified in the broad literature search, 11 studies were selected for review in this QSR, based on their qualitative findings being of specific relevance to the purpose of the QSR.

\section{Data Collection Process}

The 11 articles selected from the literature search process were read carefully. Study attributes were identified and extracted, including theoretical framework, purpose, research question, sample, sampling technique, and methods. An electronic matrix was 
constructed to organize study attributes extracted from each article. Qualitative findings were identified and underlined, and preliminary notes about possible codes were made in the margins. As described by Sandelowski and Barroso (2002), qualitative findings may be found throughout an article and are not limited to the Findings or Results sections of an article. Therefore, qualitative findings were identified to be those statements made by the authors that were a synthesis and interpretation of raw data, supported by direct quotes and field notes rather than outside literature.

A second electronic matrix was constructed to organize qualitative findings extracted from each article. Commonalities began to emerge, including catharsis, healing, empowerment, finding meaning, supportive atmosphere, and distressing but worthwhile. Over time, categories were combined under broader headings, such as therapeutic process, for clarity and to more fully capture the overall picture of the findings. Throughout the extraction and data analysis processes, individual qualitative findings were evaluated for quality and fittingness This approach is consistent with Pawson's (2006) method of evaluating the quality of qualitative findings, in which high quality findings are identified based on "appraisal in relation to the precise usage of each fragment of evidence within the review" rather than the quality of the entire study being evaluated as a whole (p. 141). Findings included for analysis were those that were amply supported by relevant, meaningful raw data (e.g., direct quotes and field notes) and deemed to be logical and insightful syntheses of existing evidence.

\section{Synthesis of Results}

Once extraction and categorization of all findings from the 11 articles was complete, major themes were identified across the studies. Data were recoded and 
recategorized as necessary to fit under more appropriate headings, and ultimately, the coded/categorized data were collapsed into the two major themes: therapeutic process and supportive atmosphere. Analytic interpretation and synthesis of data under each of the major themes then began through the process of memoing. Memoing provided a means of interpreting and synthesizing the data. This is consistent with the MEMO process (Mapping research activities, Extracting meaning from the data, Maintaining momentum, Opening communication) described by Birks, Chapman, and Francis (2008). Extensive memoing continued to reflect upon the major themes and subheadings and data within them. This allowed a more complete exploration and refinement of key elements and the connections between them.

\section{Validity}

Throughout data analysis and extraction, qualitative findings were evaluated individually for fit with the purpose of the systematic review, rather than the entire article being assessed for strengths, weaknesses, and overall quality (Pawson, 2006). Fit is essential to all stages of the research process and can be used to evaluate internal and external validity (Morse \& Singleton, 2001). This means that the data collected and methods used (e.g., berrypicking and "digging for nuggets") are consistent with the purpose of the QSR (Barroso et al., 2003; Pawson, 2006). Data that did not fit with the purpose of the QSR were excluded, such as findings related to provider's experiences of interviewing women about abuse, as this information was not central to the synthesis conducted. All 11 articles selected for analysis and interpretation contributed significantly to the main topics and themes of the QSR, and saturation was achieved to the point where no new information obtained would significantly alter the findings. 
External validity is demonstrated in that the topic of the QSR, interviewing women about abuse, could be applied to multiple settings and situations (e.g., clinics, emergency departments, shelters, and inpatient units) and is not limited to psychiatric and mental health settings.

Triangulation and reflexivity. To further promote validity, results were reviewed by a seasoned, doctorally-prepared psychiatric nurse faculty colleague, employing analyst triangulation. Triangulation of sources was achieved by including qualitative studies conducted in a variety of countries and settings, as well as in a variety of qualitative and mixed methods designs (Robert Wood Johnson Foundation, 2008). A reflexive journal was used to record thoughts, opinions, and monitor potential sources of bias throughout the data extraction and analysis process.

\section{Results}

\section{Study Characteristics}

The 11 studies included for analysis were published between the years of 1993 and 2014. They were methodologically diverse, including mixed methods, phenomenology, and elements of grounded theory. One study identified a theoretical framework that was used throughout the research process: Pennebaker, Colder, and Sharp's (1990) Inhibition-Confrontation Model of Coping (Burke Draucker, 1999). The purpose and research questions identified in each study varied, but all either directly or indirectly related to women's experience of being interviewed about abuse across the lifespan, which is the central purpose of the QSR.

The 11 studies were conducted with diverse populations of women, including rural American, urban American, Australian, Danish, and British. In ten studies, data 
were collected through focus groups and video- and audio-taped individual interviews, and one author extracted data from her previous works on the subject (Burke Draucker, 1999). Data were collected primarily in English, except in the case of select focus groups that were conducted in Spanish (Chang et al., 2005) and in the study conducted in Denmark (Mørk, Andersen, \& Taket, 2014). Data were collected in a variety of settings, including clinics, emergency departments, and shelters. In some cases, the exact number of respondents was unclear; however, it is estimated that over 2,700 women and over 300 practitioners participated in the 11 studies under review. This large number of participants is due largely to the use of large focus groups in several of the studies.

The purpose of this QSR was to thoroughly analyze, interpret, and synthesize qualitative findings related to asking women about their abuse experiences across the lifespan with the intention of understanding risks and benefits, as well as making recommendations on how to best interview women about abuse in clinical practice and how to best include female survivors of abuse and their experiences in future research endeavors. In this context, two key themes ultimately emerged from the data analysis process: supportive atmosphere and therapeutic process.

\section{Synthesis of Results}

Supportive atmosphere. Women who survive abuse want to be asked about it, but they want providers to recognize that it can be distressing to discuss (Chang et al., 2005; Mørk et al., 2014; Burke Draucker, 1999; Kondora, 1993). They consistently expect specific circumstances when deciding to disclose details of abuse, and in many cases, they put the responsibility on the healthcare provider to create the right conditions for disclosure. They expect providers to ask their partners to leave the room to create a 
safe, private atmosphere, and they expect providers to be attentive, patient, and respectful (Chang et al., 2005; Mørk et al., 2014; Wester, Wong, \& Lagro-Janssen, 2007). Somewhat paradoxically, while putting the onus on providers to take certain measures to create a suitable atmosphere for disclosing abuse, women also want to maintain autonomy throughout the process of disclosing abuse (Chang et al., 2005; Mørk et al., 2014; Kondora, 1993; Burke Draucker, 1999).

Women are often telling their story for the first time and want to share the details of their experience beyond conventional abuse screening questions (Burke Draucker, 1999; Kondora, 1993; Mørk et al., 2014). They have mixed feelings about providers emphasizing that abuse questions are part of a normal assessment that they ask every patient. Some women feel this is impersonal and report feeling like a checkbox on a sheet that a provider just needs to mark off (Mørk et al., 2014; Rhodes et al., 2007). Other women feel more comfortable with this, like they were not being targeted by the provider as someone who looks or acts like a victim and thus warrants additional questioning, and report feeling more like a typical patient being seen for a routine wellness visit (Chang et al., 2005; Salmon, Baird, \& White, 2013).

Women want to be presented with options and resources for help, whether or not they are contemplating leaving their abuser. They appreciate being given handouts and telephone numbers directly by a provider (Mørk et al., 2014), and they also appreciate having pamphlets and brochures in waiting rooms for them to pick up inconspicuously on their own (Chang et al., 2005; Malpass et al., 2014). Women expect not to be judged by the provider for not disclosing abuse, disclosing only limited information, or stating that they do not want or are not ready to leave an abuser, even when the provider has created 
a safe, confidential atmosphere for them to do so (Chang et al., 2005; Mørk et al., 2014;

Kondora, 1993; Burke Draucker, 1999; Salmon et al., 2013; Wester et al., 2007).

Whether or not they disclose abuse, women expect providers to acknowledge how difficult it is for them and appreciate when providers leave the conversation open-ended, inviting them to call when they are ready to talk (Chang et al., 2005; Malpass et al., 2014). When they do decide to disclose, women expect that providers will be empathic, respectful listeners that will validate their experiences and emotions (Kondora, 1993; Burke Draucker, 1999; Salmon et al., 2013; Wester et al., 2007).

Therapeutic process. In the presence of a supportive atmosphere, women interpret talking about abuse as a healing experience, despite being initially distressing, because they feel empowered by an increased sense of self-worth (Burke Draucker, 1999; Kondora, 1993; Mørk et al., 2014; Chang et al., 2005; Malpass et al., 2014; Valpied, Cini, O’Doherty, Taket, \& Hegarty, 2014). They find value and meaning within themselves, and they report finding a missing piece of themselves (Kondora, 1993). As a result, they are able to work toward self-acceptance and begin caring for themselves (Kondora, 1993; Valpied et al., 2014). Women also report experiencing relief, catharsis, validation, and an increase in inner strength as a result of honest disclosure about past abuse (Burke Draucker, 1999; Kondora, 1993; Spangaro, Zwi, \& Poulos, 2011; Valpied et al., 2014) Based on the qualitative findings reviewed, most women feel the benefits of talking about abuse outweigh the negatives and report little to no regret after disclosure (Kondora, 1993; Burke Draucker, 1999; Chang et al., 2005; Mørk et al., 2014; Edwards, Sylaska, \& Gidycz, 2014). Those who did report regret after disclosure tended to have prior 
experience with a statutory agency, such as Child Protective Services (CPS) (Spangaro et al., 2011).

By talking about and reflecting on their experiences, women are able to make meaning of them, often acknowledging how surviving abuse has transformed them into more emotionally and psychologically resilient individuals, and report they are able to view the reflective, healing process of talking about abuse as a celebration of the human spirit (Kondora, 1993; Burke Draucker, 1999; Valpied et al., 2014). By viewing themselves as strong individuals and survivors, they are able to make difficult decisions that result in positive life changes, such as setting boundaries with unhealthy people in their lives (Kondora, 1993; Malpass et al., 2014; Spangaro et al., 2011) Women feel that talking about abuse enables them to use their experiences to help other survivors of abuse, adding to a sense of purpose, empowerment, and increased self-esteem (Kondora, 1993; Burke Draucker, 1999; Valpied et al., 2014; Edwards et al., 2014).

\section{Discussion}

The majority of women treated in mental health settings report having experienced at least one form of abuse over their lifetime, and those in inpatient mental health facilities report the highest rates of abuse (National Center on Domestic Violence, Trauma and Mental Health, 2011; Örmon et al., 2016). These high rates of abuse are of particular importance to mental health nurses, as they typically are the first providers to interact with and interview these women in both outpatient and inpatient facilities (Örmon et al., 2016). Although collections of quantitative data exist, no known QSRs have been conducted to evaluate the qualitative data that exists on the experiences of women being interviewed about abuse they experience across the lifespan. A 
comprehensive review and understanding of both quantitative and qualitative data are essential to support the evidence-based practice of the mental health nurse. This qualitative review adds more robust, multifaceted insight into the phenomenon of interviewing women about their abuse experiences and offers concrete recommendations for psychiatric and mental health nursing practice.

Based on the results of this QSR, it appears that, while initially distressing, being interviewed about abuse is more beneficial than harmful for women, due to the cathartic, healing nature of the process of talking about abuse. Quantitative data support these findings, indicating that nurses should be actively asking about abuse in all settings, rather than assuming women will take the initiative to disclose this information (BeckerBlease \& Freyd, 2006; Berry \& Rutledge, 2016; Keeling \& Birch, 2004). Nurses are in an ideal position to create the supportive atmosphere necessary for the therapeutic process to take place, as they are ranked consistently as one of the most trusted professions in the US and receive training and extensive clinical practice related to creating safe, confidential environments for patients and therapeutic communication (Gallup, 2014). To maximize the therapeutic impact of discussing abuse, women must maintain autonomy and feel they are in a safe, confidential, and supportive environment, which largely depends on the actions, words, and tone of the health care provider. Within this supportive atmosphere, very few women report any regret after discussing abuse and are able to identify many positive outcomes, including an improved sense of self and a newly recognized sense of purpose to help other survivors of abuse.

As is consistent with quantitative findings, the qualitative data indicate that women appreciate being included in research studies that involve being interviewed 
about abuse, due to personal benefits described previously and a sense of helping others (Becker-Blease \& Freyd, 2006; Berry \& Rutledge, 2016; Keeling \& Birch, 2004). Like mental health nurses and other healthcare providers, researchers are encouraged to be mindful of their words, actions, and tone, creating a supportive atmosphere for their research participants. Researchers must seek approval from the necessary institutional review boards and ethics committees prior to conducting research in order to ensure the proper safeguards and protocols are in place to protect participants. Additionally, researchers need to respect women's autonomy and what they chose to disclose, as well as be prepared to provide resources for them.

\section{Implications for Practice}

As supported by the findings of this review, mental health nurses are strongly encouraged to ask about and document abuse in all of their interviews and assessments, as well as act as advocates and discuss reported abuse within their interdisciplinary teams. Nurses are instrumental in collecting valuable information that can then be used to tailor each individual's treatment plan and assist clinicians in providing traumainformed care to women who have experienced abuse.

The mental health nurse should take time to interview the individual in a private area, away from potential perpetrators and others who may overhear sensitive topics being discussed. The nurse should listen attentively, avoid judgment, offer reassurance, make appropriate referrals, and provide resources for women, including those with both past and current abuse histories. Mental health nurses should respect individual boundaries and encourage women to disclose only information which they feel comfortable sharing in each interaction, rather than pressuring women for information. 
Additionally, nurses must refrain from imposing their personal beliefs and opinions on survivors and must respect an individual's choice to leave or remain in an abusive situation, with the understanding that survivors are at the greatest risk for harm when they leave an abusive partner (Pinto \& Caple, 2016).

Resources should be offered to women in all stages of readiness for change, and mental health nurses should make appropriate mandated reports related to IPV as their national, state, or local government requires. In the US, less than 30 percent of states require that nurses and other clinicians notify law enforcement of suspected or confirmed IPV, independent of the survivor's wish to make a report (Durborow, Lizdas, O'Flaherty, \& Marjavi, 2010). In the majority of states, nurses making a report against the survivor's wishes are considered to be in violation of the survivor's privacy. Most states only mandate reporting when the injuries involve substantial burns or injuries caused by a deadly weapon, such as a firearm or knife (Durborow et al., 2010). This is also the case in Australia, where mandated reporting requirements vary widely across geographic jurisdictions (Mathews \& Walsh, 2014). In the UK, nurses are able to make referrals to organizations so that legal action against suspected perpetrators can be pursued, independent of the survivor wishing to make a report (Crown Prosecution Service, 2016). It is imperative that mental health nurses are thoroughly aware of the mandated reporting laws and regulations in the location in which they practice in order to provide safe, consistent care with the best possible outcomes for their patients.

\section{Limitations}

This QSR is limited to sources available in English, so the experiences of other populations of women may not be adequately represented (e.g., Asian, African, and 
South American women). Further research is encouraged to capture the experiences of these groups. Additionally, several studies included qualitative findings related to health care providers' experiences of interviewing women about abuse (Mørk et al., 2014; Rhodes et al., 2007). These findings, while important, were not central to the focus of this QSR, and warrant a separate systematic review.

\section{Conclusions}

Women appreciate being asked about abuse experiences across the lifespan and acknowledge it as a potentially healing process. Health care providers, particularly mental health nurses, are primarily responsible for creating the optimal environment for discussing abuse and are encouraged to provide options and resources to women in all stages of readiness for change. Nurses are encouraged to ask about abuse in all settings in which they may encounter women and follow up with these women whenever possible. Researchers are encouraged to include women in studies that involve asking about abuse experiences and are expected to provide a similar environment and resources.

\section{Funding}

This QSR was conducted while the author was enrolled as a $\mathrm{PhD}$ student at the University of Missouri-Columbia. Funding in the form of tuition assistance was provided by the Sinclair School of Nursing, Sinclair Fellowship, and Jonas Nurse Leader Scholar program. A grant was obtained through the International Society for the Study of Trauma and Dissociation, as well. 


\section{References}

Australian Government Department of Social Services. (2004). The cost of domestic violence to the Australian economy: Part one. Retrieved from https://www.dss.gov.au/sites/default/files/documents/05_2012/cost_of_dv_to_aus tralian_economy_i_1.pdf

Barroso, J., Gollop, C., Sandelowski, M., Meynell, J., Pearce, P., \& Collins, L. (2003). The challenges of searching for and retrieving qualitative studies. Western Journal of Nursing Research, 25(2), 153-178.

Bates, M. (1989). The design of browsing and berrypicking techniques for online search interface. Online Review, 13, 407-424.

Becker-Blease, K. A., \& Freyd, J. J. (2006). Research participants telling the truth about their lives: The ethics of asking and not asking about abuse. American Psychologist, 61(3), 218-226. doi:10.1037/0003-066X.61.3.218

Berry, K., \& Rutledge, C. (2016). Research: Factors that influence women to disclose sexual assault history to health care providers. Journal of Obstetric, Gynecologic \& Neonatal Nursing, 45, 553-564. doi:10.1016/j.jogn.2016.04.002

Birks, M., Chapman, Y., \& Francis, K. (2008). Memoing in qualitative research. Journal of Research in Nursing, 13, 68-75. doi: 10.1177/1744987107081254

Black, M. C., Basile, K. C., Breiding, M. J., Smith, S. G., Walters, M. L., Merrick, M. T., ... Stevens, M. R. (2011). The National Intimate Partner and Sexual Violence Survey (NISVS): 2010 Summary Report. National Center for Injury Prevention and Control, Centers for Disease Control and Prevention. Retrieved from http://www.cdc.gov/violenceprevention/pdf/nisvs_executive_summary-a.pdf 
Burke Draucker, C. (1992). The healing process of female adult incest survivors:

Constructing a personal residence. The Journal of Nursing Scholarship, 24(1), 48. doi:10.1111/j.1547-5069.1992.tb00691.x

Burke Draucker, C. (1999). The emotional impact of sexual violence research on participants. Archives of Psychiatric Nursing, 13(4), 161-169.

doi:10.1016/S0883-9417(99)80002-8

Centers for Disease Control and Prevention. (2016). Injury prevention and control:

Division of violence prevention. Retrieved from

http://www.cdc.gov/violenceprevention/index.html

Chang, J. C., Decker, M. R., Moracco, K. E., Martin, S. L., Petersen, R., \& Frasier, P. Y. (2005). Asking about intimate partner violence: Advice from female survivors to health care providers. Patient Education and Counseling, 59(2), 141-147.

doi:10.1016/j.pec.2004.10.008

Crown Prosecution Service. (2016). Violence against women and girls: Crime report 2015-16. Retrieved from http://www.cps.gov.uk/publications/docs/cps_vawg_report_2016.pdf

Durborow, N., Lizdas, K., O’Flaherty, A., \& Marjavi, A. (2010). Compendium of state statutes and policies on domestic violence and health care. Family Violence Prevention Fund. Retrieved from http://www.acf.hhs.gov/sites/default/files/fysb/state_compendium.pdf

Edwards, K., Sylaska, K., \& Gidycz, C. (2014). Women's reactions to participating in dating violence research: A mixed methodological study. Psychology of Violence, 4(2), 224-239. doi: 10.1037/a0034339 
Finfgeld-Connett, D. (2010). Generalizability and transferability of meta-synthesis research findings. Journal of Advanced Nursing, 66(2), 246-254. doi:10.1111/j.1365-2648.2009.05250.x

Finfgeld-Connett, D., \& Johnson, E. D. (2013). Literature search strategies for conducting knowledge-building and theory-generating qualitative systematic reviews. Journal of Advanced Nursing, 69(1), 194-204. doi:10.1111/j.13652648.2012.06037.x

Gallup. (2014). Honesty/ethics in professions. Retrieved from http://www.gallup.com/poll/1654/Honesty-Ethics-Professions.aspx

Keeling, J. \& Birch, L. (2004). Asking pregnant women about domestic abuse. British Journal of Midwifery, 12(12), 747-749.

Kondora, L. L. (1993). A Heideggerian hermeneutical analysis of survivors of incest. The Journal of Nursing Scholarship, 25(1), 11-16. doi:10.1111/j.15475069.1993.tb00747.x

Laylor, K., \& McElvaney, R. (2010). Child sexual abuse, links to later sexual exploitation/high-risk sexual behavior, and prevention/treatment programs. Trauma, Violence, \& Abuse, 11(4), 159-177. doi:10.1177/1524838010378299

Malpass, A., Sales, K., Johnson, M., Howell, A., Agnew-Davies, R., \& Feder, G. (2014). Women's experiences of referral to a domestic violence advocate in UK primary care settings: A service-user collaborative study. British Journal of General Practice, 64(620), e151-e158. doi: 10.3399/bjgp14X677527

Mathews, B., \& Walsh, K. (2014). Mandatory reporting laws. Australian Institute of Family Studies. Retrieved from https://aifs.gov.au/sites/default/files/fpl14.pdf 
Mørk, T., Andersen, P., \& Taket, A. (2014). Barriers among Danish women and general practitioners to raising the issue of intimate partner violence in general practice: A qualitative study. BMC Women's Health, 14(1), 74. doi:10.1186/1472-6874-14-74

Morse, J.M., \& Singleton, J. (2001). Exploring the technical aspects of "fit" in qualitative research. Qualitative Health Research, 11, 841-847.

National Center for Injury Prevention and Control. (2003). Costs of Intimate Partner Violence Against Women in the United States. Centers for Disease Control and Prevention.

National Center on Domestic Violence, Trauma and Mental Health. (2011). Prevalence of Intimate Partner Violence and Other Lifetime Trauma Among Women Seen in Mental Health Settings. Retrieved from http://www.nationalcenterdvtraumamh.org/wpcontent/uploads/2012/01/Warshaw-Prevalence-of-IPV-in-MH-Settings.pdf

Örmon, K., Sunnqvist, C., Bahtsevani, C., \& Torstensson Levander, M. (2016). Disclosure of abuse among female patients within general psychiatric care - A cross sectional study. BMC Psychiatry, 161-7. doi:10.1186/s12888-016-0789

Pawson, R. (2006). Digging for nuggets: How "bad" research can yield "good" evidence. International Journal of Social Research Methodology, 9(2), 127-142. doi:10.1080/13645570600595314

Pinto, S., \& Caple, C. (2016). Intimate partner violence: The process of leaving. CINAHL Nursing Guide. 
Rhodes, K., Frankel, R., Levinthal, N., Prenoveau, E., Bailey, J., \& Levinson, W. (2007). "You're not a victim of domestic violence, are you?" Provider-patient communication about domestic violence. Annals of Internal Medicine, 147(9), 620-627. doi: 10.7326/0003-4819-147-9-200711060-00006

Ring, N., Ritchie, K., Mandava, L., \& Jepson, R. (2011). A guide to synthesizing qualitative research for researchers undertaking health technology assessments and systematic reviews. NHS Quality Improvement Scotland. Retrieved from: http://www.healthcareimprovementscotland.org/his/idoc.ashx?docid=04df262cec20-40e1-aef7-d2aa3ad03c06\&version=-1

Robert Wood Johnson Foundation. (2008). Triangulation. Qualitative Research Guidelines Project. Retrieved from http://www.qualres.org/HomeTria-3692.html

Salmon, D., Baird, K., \& White, P. (2013). Women's views and experiences of antenatal enquiry for domestic abuse during pregnancy. Health Expectations. doi: 10.1111/hex.12060

Sandelowski, M., \& Barroso, J. (2002). Finding the findings in qualitative studies. Journal of Nursing Scholarship, 34, 213-219.

Spangaro, J., Zwi, A., \& Poulos, R. (2011). "Persist. persist.”: A qualitative study of women's decisions to disclose and their perceptions of the impact of routine screening for intimate partner violence. Psychology of Violence, 1(2), 150-162. doi: $10.1037 / \mathrm{a} 0023136$

U.S. Department of Health and Human Services, Administration for Children and Families. (2012). Child Maltreatment 2012. Retrieved from http://www.acf.hhs.gov/sites/default/files/cb/cm2012.pdf 
U.S. Department of Justice. (2013). Intimate Partner Violence: Attributes of Victimization, 1993-2011. Retrieved from http://www.bjs.gov/content/pub/pdf/ipvav9311.pdf

Valpied, J., Cini, A., O’Doherty, L., Taket, A., \& Hegarty, K. (2014). “Sometimes cathartic. Sometimes quite raw": Benefit and harm in an intimate partner violence trial. Aggression and Violent Behavior, 19(6), 673-685. doi:

10.1016/j.avb.2014.09.005

Walby, S. (2009). The cost of domestic violence: Up-date 2009. Retrieved from http://www.lancaster.ac.uk/fass/doc_library/sociology/Cost_of_domestic_violenc e_update.doc

Wester, W., Wong, S., \& Lagro-Janssen, A. (2007). What do abused women expect from their family physicians? A qualitative study among women in shelter homes. Women \& Health, 45(1), 105-119. doi: 10.1300/J013v45n01_07

World Health Organization. (2016). Violence against women. Retrieved from http://www.who.int/mediacentre/factsheets/fs239/en/ 


\title{
CHAPTER FOUR
}

\section{WOMEN WITH DISSOCIATIVE IDENTITY DISORDER WHO EXPERIENCE \\ INTIMATE PARTNER VIOLENCE}

\author{
Abstract \\ Introduction \\ No known qualitative findings currently exist relating to the process by which women \\ with dissociative identity disorder (DID) cope with the experience of intimate partner \\ violence (IPV). This is despite the fact that women with DID are significantly more \\ likely than women in the general population to experience IPV. \\ Aim/Question
}

The purpose of this qualitative investigation was to explicate the experiences of women with DID who experience IPV and describe how they cope.

Method

Grounded theory was used to conduct this investigation. Purposive sampling was used to recruit participants $(\mathrm{N}=5)$ for face-to-face semi-structured interviews. Verbatim transcripts were coded and categorized, and reflective memos were developed to explicate substantive categories.

Results

To manage their lives with IPV, women with DID employ coping strategies that are consistent with their diagnosis, such as switching and dissociating. These coping mechanisms reflect past self-preservation strategies that were developed in association with severe childhood maltreatment. 


\section{Discussion}

Women with DID who experience IPV seek to mitigate and safeguard themselves from current danger by using strategies they developed as maltreated children. Nurses can use these findings to better recognize and understand the motivations and behaviors of women with DID who experience IPV. Additional research is recommended to understand how women with DID cope with IPV and to enhance assessment and intervention strategies.

Keywords: abuse, domestic violence, intimate partner violence, dissociative identity disorder, coping, self-protection, grounded theory

\section{Accessible Summary}

\section{What is known on the subject}

- Survivors of child maltreatment, including women with dissociative identity disorder (DID), are more likely to experience intimate partner violence (IPV) than the general population.

- No known qualitative studies have been conducted to explore how women with DID cope with IPV.

\section{What this paper adds to the existing knowledge}

- Women with DID use self-preservation strategies that they developed during childhood to cope with IPV in adulthood.

- Women with DID employ switching and dissociating to cope with IPV.

\section{What are the implications for practice}

- Nurses are urged to take into consideration the unique strategies that women with DID use to cope with IPV. 
A diagnosis of dissociative identity disorder (DID) can result from severe and sustained abuse and neglect that begins at a very young age (American Psychiatric Association [APA], 2013). It is estimated that a diagnosis of DID affects about one percent of the population (over three million Americans), making DID as common as schizophrenia (Brand, Loewenstein, \& Lanius, 2014).

All forms of child maltreatment are well documented risk factors for exposure to intimate partner violence (IPV) in adulthood, which can lead to exacerbated mental illness symptoms, increased incidence of psychiatric hospitalization, and increased suicidality (Laylor \& McElvaney, 2010). It is estimated that one in four women will experience IPV at some point in her life (Black et al., 2011). In the United States (U.S.), over 200,000 women are raped by an intimate partner, and approximately 1.3 million women are physically assaulted by an intimate partner each year (Black et al., 2011).

Following child maltreatment, quantitative findings suggest that dissociation plays a role in increasing the risk of experiencing IPV as an adult (Webermann, Brand, \& Chasson, 2014). Prior to this investigation, no known qualitative research had been conducted to explore the relationship between DID and IPV. Therefore, current knowledge relating to women with DID who experience IPV may not be accurate or sufficient. This is particularly concerning because the incidence of IPV among survivors of childhood maltreatment is at least double that of the general population (Arnow, 2004; Webermann et al., 2014).

\section{Conceptual Framework}

Betrayal trauma theory (BTT; Freyd, 1994) was used as a framework for this investigation. BTT (1994) explicates the need for individuals who experience child 
maltreatment to develop dissociative amnesia for overwhelming abuse and neglect experiences in order to survive. Survivors are often dependent on abusers for basic needs (e.g., food and shelter), so it behooves them not to retaliate towards abusers and risk worsening the maltreatment. BTT was appropriate for this investigation because it relates to the unique dissociative experiences of women with DID as an adaptive survival mechanism. BTT was used to develop interview questions, analyze data, and evaluate findings.

\section{Aim and Research Questions}

The primary aim of this qualitative inquiry was to explicate coping processes of women with DID who have experienced IPV. A secondary aim was to describe the experiences of women with DID and the factors that contribute to their continued engagement in abusive relationships in adulthood. The researcher sought to answer the following questions:

1. How do women with DID cope with IPV?

2. What are the experiences of women with DID who are exposed to IPV, and what factors contribute to continued exposure to IPV?

\section{Methods}

Grounded theory was used to conduct this investigation. Prior to beginning data collection, the study was approved by the Health Sciences Institutional Review Board at the University of Missouri-Columbia.

\section{Sampling}

Purposive sampling was used to recruit participants. To be included in the study, women were required to be IPV survivors, diagnosed with DID, English-speaking, and 
aged 18 or older. Participants received their diagnosis of DID from experts in the field, in accordance with guidelines in the Diagnostic and Statistical Manual of Mental Disorders (DSM-5; American Psychiatric Association, 2013). To aid in the diagnostic process, the Structured Clinical Interview for DSM-IV Dissociative Disorders Revised (SCID-D-R; Steinberg, 1994) was used, which is the current gold standard. For safety reasons, individuals were excluded from the study if they had been psychiatrically hospitalized within the last year and/or if they were not currently under the care of an outpatient clinician (e.g., therapist, psychiatrist, or psychologist).

\section{Recruitment}

Participants were referred to the researcher by psychiatrists, psychologists, and therapists who treat women with DID at a private psychiatric hospital in the northeastern area of the United States. These DID and IPV experts assisted the researcher to recruit women who were well known to them and stable in outpatient treatment for at least one

year. Stability criteria included minimal dissociation, a high level of communication and cooperation among personality states, and no psychiatric hospitalizations for at least one year.

Clinicians provided potential participants with the researcher's contact information, and they contacted the researcher by telephone and email about participating in the study. The researcher then ensured inclusion criteria were met and set up an appointment to enroll the individual in the study. The researcher met participants in a private office at the local private psychiatric hospital. The researcher explained the study, answered all of the participants' questions, and obtained written consent. 


\section{Data Collection}

Consultations and individual interviews with the researcher's doctoral committee and DID/IPV experts were conducted to develop and refine interview questions, while considering concepts from BTT (Freyd, 1994). Sample interview questions are presented in Table 1.

Data were collected by the researcher via face-to-face interviews in a private office at the local private psychiatric hospital. Follow-up telephone interviews were completed with four out of five participants to obtain clarification and discuss emerging themes. All tape-recorded interviews were semi-structured and guided by open-ended questions. Initial interviews averaged 55 minutes (range 48 to 72), and follow-up telephone interviews averaged 18 minutes (range 11 to 22). Each participant received a copy of the consent, a safety card containing referral information for women who experience IPV, a list of local IPV resources and telephone numbers, and a \$30 gift card for participating.

\section{Data Analysis}

All recordings were transcribed by the researcher, and coding and categorizing was completed using electronic tables. Sample codes and categories are shown in Table 2. Open coding was conducted, and basic core concepts emerged. Codes were then iteratively grouped together to form categories (i.e., axial coding). Memoing occurred throughout the data analysis process to further explicate categories (Richards \& Morse, 2013). During data analysis, the researcher noted emerging codes and concepts that were consistent with BTT (Freyd, 1994) and made an effort to inquire further about these in subsequent interviews. 


\section{Validity}

Each researcher brings his or her own personal thoughts, emotions, philosophies, assumptions, and experiences to the table when conducting research. To conduct a valid study in spite of these factors, the researcher must be self-aware, acknowledge the impact these personal beliefs may have on the research being conducted, and take steps to avoid bias (Berger, 2013). To ensure validity, the researcher used reflexivity to continuously examine potential researcher bias throughout all stages of data collection and analysis (Berger, 2013; Doyle, 2013). Validity was also enhanced based on the richness of interview data. Follow-up telephone calls allowed the researcher to present participants with interpretations of their previous statements and emerging themes for confirmation of accuracy. The follow-up calls also gave the participants an opportunity to add or clarify information, further enhancing the quality of the data.

\section{Findings}

Five participants completed the study. All were Caucasian females with an average age of 41 years (range 38 to 65 ). Two were divorced with a past history of IPV, and two were married and currently experiencing IPV. One had a history of IPV but had never been married. Two women experienced IPV with multiple partners, and three women experienced IPV with a single partner. Co-morbid mental illnesses within the sample included posttraumatic stress disorder (PTSD; N=3), anorexia nervosa $(\mathrm{N}=3)$, major depressive disorder (MDD; $\mathrm{N}=3$ ), obsessive-compulsive disorder ( $\mathrm{OCD} ; \mathrm{N}=1)$, and bipolar disorder $(\mathrm{N}=1)$.

Analysis of the transcribed interviews resulted in the following substantive categories: childhood maltreatment and its impact, use of self-states to cope with IPV, 
worsening symptoms, and desire for resources. Childhood maltreatment and its impact are discussed first.

\section{Childhood Maltreatment and its Impact}

All participants reported severe childhood maltreatment by an immediate family member, including parents and siblings. Some reported abuse by unrelated individuals, which included ritual abuse and trafficking. All participants reported witnessing abuse in childhood, including intimate partner violence between parents, child maltreatment of siblings, and trafficking of other children. As a result, participants described the experience of lacking a family, or as one participant put it, "There was no home." This idea of a damaged, incomplete, or missing home was associated with a sense of increased vulnerability. One participant explained:

Being molested by a stepfather, being very abused by a brother, as far as physically. Very physically. A stepbrother molested me. Just a broken home. I mean, I was definitely seeking attention, so that made me more vulnerable, and so I definitely was a target [for an abuser].

Another participant described her experience with her parents in the following way. "They were the only people I had ever associated with, and they were abusive, and I was trying desperately to get away from them. So, I jumped into the first relationship that came along, even though he was abusive."

Participants acknowledged that this experience of lacking family support, or having an outright abusive family, limited their options when experiencing IPV. "I would not go back to my parents' house, even though they were only 45 minutes away, 
because they're abusive, too." Another participant explained the situation in the following manner.

I never had a family, so that [being married to an abuser] gave me family security. You know, I never really had a mother or a father figure, so it just made me feel like a complete family, like I wasn't abandoned or alone.

This intense fear of abandonment was a prominent theme throughout each interview. Participants described the unbearable fear of being alone as their "biggest horror," even while enduring serious abuse and a partner's infidelity. They reported being "so afraid and so obsessed" with the idea of being alone, even reporting recurrent nightmares of their partner abandoning them. As a result, fear of abandonment was cited as a major barrier to ending an abusive relationship.

Participants also endorsed the idea that abuse was familiar and expected, due to the very early onset and sustained experience of child maltreatment. After years of experiencing and witnessing abuse, participants came to view it as normal. As one participant put it, "I don't think I noticed it [being hit by a partner] as being an odd thing." Another said, "Just the fact of being used to being hit...I guess there are homes where people don't scream at each other? It's just really hard to believe." One participant described the experience of first learning that abuse was not normal by watching a popular talk show as an adult. Along with this idea, participants discussed the implicit understanding that abuse was not to be talked about outside of the home, a belief that was carried into adulthood. 


\section{Use of Self-States to Cope with IPV}

Participants employed coping strategies for IPV that were consistent with coping strategies that they used for self-protection in childhood and that are associated with DID. Self-states, or "parts," that developed as a result of overwhelming and intolerable childhood maltreatment were unconsciously and consciously called upon to cope with IPV. For example, some participants described self-states that dealt with intimacy. "I had parts [self-states] that were assigned to have sex with him, but they were like trafficked parts and prostituted parts. And they always felt like they were being raped. It felt very much like sexual abuse.”

Others described switching to child self-states (e.g., hiding or curling up on the floor in tears) or aggressive, sometimes masculine, self-states (e.g., confronting, provoking, hitting the abuser) when experiencing verbal and physical abuse from a partner. Some participants expressed confusion and surprise at their varied reactions to IPV, particularly if they were unaware of the function of self-states and received their DID diagnosis after the abusive relationship had ended. Switching between self-states was a mechanism for participants to protect both themselves and their self-states when they were unable to handle IPV.

Participants also developed new self-states as a result of IPV experiences.

I've always had this experience with my mother and stuff like that, who was one of my abusers. She would scream at me, and I would be sort of like, sucked out of the room, and my brain would just feel like it was shattering into a million pieces. It just felt like I was splintering off, and it was just like the weirdest 
sensation. I sometimes get that with him [abuser], where I feel like new parts are breaking off and being created.

Another participant described the development of a new self-state when she met her abusive husband. This self-state loved the abuser unconditionally and had no memory of past abuse.

Conflicting beliefs among self-states were cited as both impediments to ending abusive relationships and justifications for remaining in abusive relationships. While some self-states may love an abuser, others may harbor extreme hatred and homicidal ideation towards them, with a broad spectrum of feelings and beliefs in between the two extremes. One participant explained her experience in this way. "There are parts that are going to die, believe will die, when he [abuser] walks out the door. I don't know why they have more power than any other parts inside, but they do." She went on to discuss how one particular self-state who loved her husband "unconditionally" played a role in continuing the abusive relationship by begging him to come back after he left her for another woman.

Another participant described the chaos and confusion that can result from varying beliefs among self-states in the following manner. "When we're [participant and her partner] fighting, especially internally, it just gets so chaotic with parts and all having different feelings about it and reacting different ways."

Dissociation and memory impairments. All participants endorsed experiencing increased dissociation and memory impairment during IPV, which is consistent with childhood coping mechanisms. By "disconnecting" or "going away" during episodes of abuse, participants were self-protecting. Paradoxically, this self-protection mechanism 
also appeared to intensify conflict with an abusive partner. For instance, one participant stated: "I'm so disorganized, and I can never find anything or remember anything, so that causes fights." Participants reported that dissociation limited their ability to sense and flee from danger in some cases. "When I'm in a fight with him, I dissociate so badly, I know I cannot get behind the wheel [of a car]."

\section{Worsening Symptoms}

Experiencing IPV worsened the mental health of participants. As described previously, they endorsed more frequent and rapid switching between self-states, formation of new self-states, increased dissociation and time loss, and more pronounced amnesia. Participants also reported increased suicidality and worsening of co-morbid conditions, such as depression and eating disorders. One participant described increased "depression, self-hate, self-abuse" and "sleeping and smoking my head off." Another woman described her situation in this way.

It activates my parts a lot. Probably still does cause new splintering. I've been very suicidal myself... and if I think about all the times he [abuser] told me I should do it [kill self] or how he would do it [kill participant]...that really doesn't help my case very much. It feels like a jackhammer in my brain.

Abusers frequently used a history of mental illness against participants and blamed them for problems in the relationship. For example, abusers would label participants as crazy, sick, forgetful, unreliable, and inconsistent. "I can't trust you because you're crazy. You have all these problems, so how do I know that anything you say is true?" 
In some cases, abusers were intrusive in participants' treatment and therapy or blocked participants' access to mental health care, further limiting their coping options. "He [abuser] was very angry the first time I got hospitalized [for an eating disorder]. He did not want me to go." One participant described her interactions with her abusive husband following her therapy sessions in the following manner.

He would follow me... all around the house asking what I talked about in therapy. Saying things like, you need to tell me because I'm the only one who can help you because I love you and I know you the best and she [therapist] doesn't know you and she doesn't care about you.

\section{Desire for Resources}

When asked what they would create for other women like themselves if given a magic wand, participants requested resources to help them cope with IPV. Chief among them was more healthcare professionals who are trained to provide trauma-informed care for IPV survivors with DID. "I don't have any doctors who will see me or who know how to treat me. I wish.” Another participant described her experience in the following way.

So, after my last assault with [ex-husband], I went to two hospitals. First, I went to [Hospital 1], and they didn't do any tests or anything. They just let me go. They didn't do any kind of screening. So, I was thinking, if there was more funding to train nurses about this kind of stuff, that would be good. Another participant recommended "some kind of residential place where you could go with your kids and be safe. Not like a traditional shelter, but like a really nice comfortable safe place... where there's treatment providers around.” This statement 
reflected the participants' overall dissatisfaction with traditional shelters. Other participants described shelters as "horrible" and "not helpful." One woman stated, "I called the [local domestic violence shelter] during one of our bad times, and whoever answered the phone told me I couldn't be serious. That this wasn't something worthy of domestic violence, and I should be happy that it's not a lot worse."

Other recommendations included financial assistance and both in-person and online peer support groups. Participants reported, "even Facebook can be good" and "I wish I had heard the story from someone like me.” Spiritual leaders and faith-based organizations were also identified as positive sources of support.

\section{Discussion}

The experiences and coping strategies described in this study are consistent with BTT (Freyd, 1994). According to Freyd, maltreated children learn to respond to abuse and neglect in a way that will not worsen their maltreatment, particularly because they rely on caregivers for food, shelter, and other necessities. As such, children adaptively develop dissociative amnesia for trauma experiences, rather than fighting back. It is feasible that women with DID who experience IPV developed dissociative amnesia as maltreated children and may continue to do so when experiencing abuse as adults. The findings from this study support this, indicating that women with DID do experience increased dissociation and amnesia while in an abusive relationship.

Women with DID who experience IPV endorse multiple sources of perceived and actual danger, which can be abstract (e.g., fear of abandonment) or concrete (e.g., violent partner). They seek to mitigate and safeguard themselves by using strategies that are similar to those they employed for self-protection as maltreated children. While these 
self-protection strategies may have been necessary for survival in childhood, they have the potential to make women more vulnerable to IPV in adulthood. For example, switching to a vulnerable child self-state during IPV may limit the woman's ability to detect danger and self-protect. Switching to an aggressive self-state during IPV may increase the risk for bidirectional IPV. Having multiple self-states with a variety of mixed feelings about an abuser further complicates the already complex decision to leave or stay with an abuser.

About $70 \%$ of individuals with DID attempt suicide as outpatients (APA, 2013), so exacerbated mental illness symptoms and increased suicidality resulting from IPV are critical concerns. Lack of knowledge about this pathological process tends to delay accurate diagnosis and treatment of DID (Chu et al., 2011). When appropriate treatment is delayed, women with DID may experience catastrophic outcomes.

\section{Implications for Practice and Research}

Practice. The women in this study reported remaining in abusive relationships for many of the same reasons that are commonly cited in the literature: lack of housing, lack of transportation, financial dependency, desire to keep the family unit intact, child custody concerns, and concern for safety (Black et al., 2011; Bradbury-Jones, Taylor, Kroll, \& Duncan, 2014; Webermann et al., 2014). Thus, nurses should take the initiative to assess for DID along with abuse in settings in which they are likely to encounter highrisk women. Nurses should inquire about a history of childhood maltreatment. Assessment should also include questions about memory, amnesia, and time loss. For individuals known to have DID, nurses are urged to inquire about the frequency of switching between self-states, as well as the patient's perceived control over switching. 
Due to the risk for increased mental health problems, nurses should assess for increased self-harm impulses and suicidality. Nurses should also be alert for comorbidities, such as an increase in depressive and/or eating disorder symptoms.

These assessments should be performed in a confidential, compassionate, and nonjudgmental manner. Autonomy is paramount, and nurses should respect how much information survivors are willing to disclose. Along those lines, nurses should never pressure survivors for more information, nor pressure them to report or leave an abuser. Nurses should respect a survivor's readiness to make a change and follow up consistently in subsequent interactions or appointments, while offering reassurance and support. In addition, nurses are encouraged to become familiar with barriers experienced by IPV survivors with DID, such as the aforementioned, and be prepared to provide information on appropriate resources for support.

Dissociative disorders are not discussed extensively in the majority of prelicensure nursing programs, so nurses may not feel comfortable working with this population (Loewenstein \& Wait, 2008). Participants in this study specifically recommended increased training for nurses and other healthcare providers related to both DID and empathic care for IPV survivors. Nurses would benefit from continuing education on DID and other dissociative disorders, including etiology, symptoms, prevalence, recommended interventions, and the increased risk for experiencing IPV. Improved and more widely available training in trauma-informed care may improve nurses' ability to recognize and sensitively respond when treating individuals with DID.

Research. Additional qualitative research is warranted with a larger sample. A larger sample would allow for further development of the substantive categories that were 
identified in this study. It would also allow for exploration of incidental evidence that emerged from this investigation, relating to potential intervention strategies (e.g., involvement of law enforcement, appointment of advocates, and marriage counseling). Nurses are urged to remain abreast of current research in this area, to make appropriate referrals to resources that will have the most benefit for this population.

All participants reported at least one comorbid mental health problem, with PTSD and anorexia nervosa being the most common ( $\mathrm{N}=3$ for each). In addition to DID, it is possible that these comorbid conditions may have had an impact on the process of coping with IPV. To improve care of women with DID who experience IPV, this confluence of diagnoses requires further investigation.

\section{Limitations and Strengths}

Limitations. The greatest limitation was the small sample size. Additionally, all participants were middle-aged, Caucasian females, and they were recruited from the same location. The small sample size, homogeneity of the sample, and limited geographic scope compromise the transferability of the study findings. Recruiting and interviewing additional diverse participants would strengthen the quality of the study and improve the validity and transferability of the results.

All research relying on self-report is limited by the possibility of recall bias and incomplete or inaccurate participant responses, which may be compounded in a population of individuals with DID who endorse varying degrees of memory impairment. That aside, the women who participated in this investigation appeared to be forthcoming when they were unable to remember details of an event or they could not provide a complete answer to a question. 
Strengths. Despite limitations, findings from this investigation add valuable information to the existing literature on the experiences and coping strategies of women with DID. Middle-aged, Caucasian females are the group that most commonly presents with DID, so this investigation contributes important insights that are relevant to the experiences of that demographic (Brand et al., 2009). Overall, there is a dearth of literature relating to IPV survivors diagnosed with DID, and the findings from this study have the potential to benefit this under-researched and difficult-to-reach population. The findings also illuminate future directions for research with this vulnerable group.

\section{Conclusions}

In addition to more commonly known coping mechanisms, women with DID employ strategies consistent with their diagnosis of DID, such as switching and dissociating, to cope with IPV. These DID-specific coping mechanisms reflect past selfpreservation strategies resulting from severe childhood maltreatment. To improve care for this extremely vulnerable and underserved population, nurses are urged to educate themselves about dissociative disorders and recognize the potential need for adapted interventions and referrals. Finally, additional research is warranted to enhance the care of women with DID who experience IPV.

\section{Funding}

This study was conducted while the author was enrolled as a $\mathrm{PhD}$ student at the University of Missouri-Columbia, as part of her dissertation research. Funding in the form of tuition assistance was provided by the Sinclair School of Nursing, Sinclair Fellowship, and Jonas Nurse Leader Scholar program. A research grant was obtained 
through the International Society for the Study of Trauma and Dissociation to support the PI's dissertation research, as well. 


\section{References}

American Psychiatric Association. (2013). Diagnostic and statistical manual of mental disorders $\left(5^{\text {th }}\right.$ ed.). Washington, DC: American Psychiatric Publishing.

Arnow, B.A. (2004). Relationships between childhood maltreatment, adult health and psychiatric outcomes, and medical utilization. Journal of Clinical Psychiatry, 65. Retrieved from http://www.ncbi.nlm.nih.gov/pubmed/15315472

Berger, R. (2013). Now I see it, now I don't: Researchers position and reflexivity in qualitative research. Qualitative Research, 15(2), 219-234.

Black, M.C., Basile, K.C., Breiding, M.J., Smith, S.G., Walters, M.L., Merrick, M.T., Chen, J., \& Stevens, M.R. (2011). The national intimate partner and sexual violence survey (NISVS): 2010 summary report. Atlanta, GA: National Center for Injury Prevention and Control, Centers for Disease Control and Prevention. Retrieved from https://www.cdc.gov/violenceprevention/pdf/nisvs_report2010a.pdf

Bradbury-Jones, C., Taylor, J., Kroll, T., \& Duncan, F. (2014). Domestic abuse awareness and recognition among primary healthcare professionals and abused women: A qualitative investigation. Journal of Clinical Nursing, 23, 3057-3068. doi: 10.1111/jocn.12534

Brand, B.L., Classen C., Lanius, R., Loewenstein, R., McNary, S., Pain, C., \& Putnam, F. (2009). A naturalistic study of dissociative identity disorder and dissociative disorder not otherwise specified patients treated by community clinicians. Psychological Trauma: Theory, Research, Practice, \& Policy, 12(2), 153-171. doi: $10.1037 / \mathrm{a} 0016210$ 
Brand, B.L., Loewenstein, R.J., \& Lanius, R.A. (2014). Dissociative identity disorder. In G. Gabbard (Ed.), Gabbard's Treatments of Psychiatric Disorders (pp. 439-458). Washington, D.C.: American Psychiatric Publishing.

Chu, J.A., Dell, P.F., Van der Hart, O., Cardeña, E., Barach, P.M., Somer, E., ...Twombly, J. (2011). Guidelines for treating dissociative identity disorder in adults, third revision. Journal of Trauma \& Dissociation, 12, 157-187.

Doyle, S. (2013). Reflexivity and the capacity to think. Qualitative Health Research, 23 (2), 248-255.

Freyd, J.J. (1994). Betrayal trauma: Traumatic amnesia as an adaptive response to childhood abuse. Ethics \& Behavior, 4, 307-329.

Laylor, K., \& McElvaney, R. (2010). Child sexual abuse, links to later sexual exploitation/high-risk sexual behavior, and prevention/treatment programs. Trauma, Violence, \& Abuse, 11, 159-177. doi:10.1177/1524838010378299

Loewenstein, R., \& Wait, S. (2008). The trauma disorders unit. In Textbook of Hospital Psychiatry (pp. 103-118). Washington, D.C.: American Psychiatric Publishing. Morse, J. (2015). "Data were saturated..." Qualitative Health Research, 25, 587-588. Richards, L. \& Morse, J. (2013). Readme first for a user's guide to qualitative methods. Los Angeles, CA: SAGE.

Steinberg, M. (1994). Structured clinical interview for DSM-IV dissociative disorders revised. Washington, DC: American Psychiatric Press.

Webermann, A.R., Brand, B.L., \& Chasson, G.S. (2014). Childhood maltreatment and intimate partner violence in dissociative disorder patients. European Journal of Psychotraumatology, 5, 1-8. doi: 10.3402/ejpt.v5.24568 


\section{Table 1}

\section{Sample Interview Questions}

\begin{tabular}{|l|l|}
\hline Interview Type & Interview Guide Samples \\
\hline Initial face-to-face interview & $\begin{array}{l}\text { Describe resources you have used to cope } \\
\text { with abusive intimate partners. }\end{array}$ \\
$\bullet$ & $\begin{array}{l}\text { Describe factors that you think might } \\
\text { contribute to your exposure to abusive } \\
\text { intimate partner relationships. }\end{array}$ \\
& $\begin{array}{l}\text { Describe barriers that prevent you from } \\
\text { leaving abusive intimate partner } \\
\text { relationships. }\end{array}$ \\
\hline Follow-up telephone interview & $\begin{array}{l}\text { Several women I have interviewed } \\
\text { mentioned that a barrier to leaving an } \\
\text { abusive partner is an intense fear of } \\
\text { abandonment that they feel stems from } \\
\text { their childhood abuse. Do you think that } \\
\text { applies to your experiences? }\end{array}$ \\
If yes, can you tell me more about that?
\end{tabular}




\section{Table 2}

Sample Link Between Category, Codes, and Data

\begin{tabular}{|c|c|c|}
\hline Category & Select Codes & Select Examples from the Data \\
\hline $\begin{array}{l}\text { Impact of Childhood } \\
\text { Experiences }\end{array}$ & $\begin{array}{l}\text { Fear of Abandonment } \\
\text { Child Maltreatment }\end{array}$ & $\begin{array}{ll}\text { - } & \text { Dreading being alone } \\
\text { - } & \text { Lacking a family } \\
\text { - } & \text { Incomplete family } \\
\text { - } & \text { Broken home } \\
\text { - } & \text { Witnessing a target } \\
\text { - } & \text { Waiting for abuse }\end{array}$ \\
\hline
\end{tabular}




\section{CHAPTER FIVE}

\section{CROSS-CHAPTER SUMMARY: CONCLUSIONS AND IMPLICATIONS FOR PRACTICE AND RESEARCH}

Quantitative data reflect that women with dissociative identity disorder (DID) are significantly more likely than the general population to experience intimate partner violence (IPV; Webermann, Brand, \& Chasson, 2014). At the time this study was conducted, no known qualitative data existed on the process by which women with DID cope with the experience of IPV, and there were no known guidelines for nursing practice and care of these individuals. Chapter One provides an introduction and brief summary of existing knowledge on the key components of this inquiry: child maltreatment (CM), DID, IPV, and betrayal trauma theory (BTT; Freyd, 1994). Chapter One also includes specific aims and research questions designed in an effort to address deficits in the scientific literature and explicate how women with DID cope with IPV.

Chapter Two is a review of the literature that examines the link between CM and the risk for experiencing IPV in adulthood. The majority of evidence found in the 28 articles reviewed for Chapter Two supports the link between CM and IPV in a variety of different populations. Overwhelmingly, CM survivors are at a higher risk for experiencing IPV in adulthood, which supports the need for the qualitative study that was conducted with women with DID and reported in Chapter Four.

The qualitative systematic review (QSR) in Chapter Three was conducted in an effort to address concerns about interviewing vulnerable populations about an emotionally-laden phenomenon, or more specifically, asking women about their abuse experiences. Synthesis of qualitative findings demonstrated that women find it more 
beneficial than harmful to be interviewed about abuse, particularly in a safe, confidential environment in which they can maintain autonomy. They report that talking about their abuse experiences can be therapeutic and cathartic, and they identified positive outcomes and few regrets. Based on the findings from the QSR in Chapter Three, it was decided that a qualitative study using face-to-face interviews could be conducted safely with a population of women with DID to determine how they cope with IPV.

Chapter Four explicates major findings from this qualitative investigation. Women with DID who experience IPV endorse multiple sources of perceived and actual danger, which can be concrete (i.e., a violent partner) or more abstract (i.e., a fear of abandonment). They seek to mitigate and safeguard themselves from current danger by using strategies they employed for self-protection as maltreated children. In addition to more commonly known coping mechanisms, women with DID employ strategies consistent with their diagnosis of DID, such as switching and dissociating, to cope with IPV. Consistent with BTT (Freyd, 1994), these specific coping mechanisms reflect past self-preservation strategies that were used during episodes of childhood maltreatment. Switching, dissociating, dissociative amnesia, and the creation of new self-states are selfprotection strategies employed to protect the women themselves and their self-states.

\section{Strengths and Limitations}

\section{Strengths}

At the time the study was conducted, this was the only known qualitative inquiry of its kind exploring the coping processes of women with DID who experience IPV. In casual conversations that occurred before and after the semi-structured interviews, participants bemoaned the lack of available information and quality research related to 
their diagnosis and life experiences. One participant compared providers' lack of knowledge about DID and IPV to being admitted to the hospital to receive treatment for diabetes, yet "nobody knows that you need insulin, knows how to administer it, or knows how to do nutrition teaching."

Participants readily provided valuable details about their lives and experiences to bolster a scant body of nursing knowledge on the coping processes of women with DID who experience IPV. Despite some challenges accessing this population, rich data were obtained from participants and clear concepts emerged from the data. Participant responses also generated insight into the need for future investigations that focus on the needs of women with DID who experience IPV. This is consistent with findings from the QSR in Chapter Three, which indicated that abuse survivors appreciate being asked about their experiences, and researchers should design and include them in research studies related to abuse.

\section{Limitations}

Regarding Chapter Four, the greatest limitation was the small sample size. Additionally, all participants were middle-aged, Caucasian females. All participants were recruited through mental health providers at one private psychiatric hospital located in the eastern U.S. All participants were survivors of IPV in heterosexual relationships, although the literature demonstrates that IPV affects homosexual and bisexual individuals at least equally as often (Koeppel \& Bouffard, 2014). The small sample size, homogeneity of the sample, and limited geographic scope compromise the transferability of the study findings. Similarly, the QSR in Chapter Three included qualitative studies that had been conducted with primarily American and European women. Including the 
experiences of additional, diverse participants (e.g., non-heterosexual women, transgendered women, women of color, and women from various areas of the world) would strengthen the quality of the study and improve the validity and the transferability of the results. Indeed, the findings compiled in the literature review in Chapter Two suggest that these and other minority groups are more likely to experience IPV with a history of CM and warrant inclusion in future studies.

Additionally, all research relying on self-report is limited by the possibility of recall bias and incomplete or inaccurate participant responses, which may be compounded in a population of individuals with DID who endorse varying degrees of memory impairment. In general, participants were forthcoming with the researcher and openly verbalized when they were unable to remember details of an event or could not provide a complete answer to a question. Although it was not a large financial sum, it is also possible that the gift card incentive for participation in the study reported in Chapter Four compromised the validity of the participants' responses to the researcher.

\section{Implications for Nursing}

The women interviewed for this study reported remaining in abusive relationships for many of the same reasons that are commonly cited in the literature: lack of housing, lack of transportation, financial dependency, desire to keep the family unit intact, child custody concerns, and concern for safety (Black et al., 2011; Bradbury-Jones, Taylor, Kroll, \& Duncan, 2014; Webermann et al., 2014). Abuse screening must occur in all settings in which nurses encounter patients, especially with high-risk populations like women and the mentally ill. Nurses must be familiar with common barriers that IPV survivors experience, such as the aforementioned, and be prepared to provide 
nonjudgmental care and appropriate resources for support. Nurses must also make appropriate referrals to interdisciplinary team members when women need higher levels of support and intervention, moving toward a culture of holistic, coordinated care.

Improved and more widely available training in trauma-informed care may improve nurses' ability to recognize and sensitively respond when treating individuals with DID. Nurses would benefit from continuing education on DID and other dissociative disorders, including etiology, prevalence, recommended interventions, and the increased risk for experiencing IPV. Dissociative disorders are not discussed extensively, if at all, in the majority of basic pre-licensure nursing programs, so nurses may not feel comfortable working with this population (Loewenstein \& Wait, 2008). Participants in this study specifically recommended increased training for nurses and other healthcare providers related to both DID and empathic care for IPV survivors, based on both positive and negative personal experiences. Healthcare providers must recognize that one approach may not be helpful for every survivor of IPV. Nurses should remain abreast of current research in this area, so as to make appropriate referrals to resources that will have the most benefit for this population. As discussed extensively in Chapter Two, nurse-midwives are in need of additional training and education, as well, particularly because of the intimate care they provide to women.

As part of increased training and continuing education for nurses, common comorbidities and related factors, specifically post-traumatic stress disorder (PTSD) and substance abuse, should be discussed in relation to dissociative disorders and IPV. Due to the high percentage of IPV survivors who also have PTSD and substance abuse issues, nurses should have a higher index of suspicion for related problems when assessing 
patients presenting with one of these complaints and perform comprehensive screening (Engstrom, El-Bassel, \& Gilbert, 2012; United States Department of Justice, 2013). Nurses must also be trained to assess for more insidious forms of IPV that frequently go undetected: verbal, emotional, and psychological abuse. Participants reported that these specific forms of abuse were more damaging than physical or sexual abuse because they were constant and pervasive. They also reported some hesitancy and shame in reporting these types of abuse, fearing they would not be believed or taken seriously. These reports are consistent with existing literature, which demonstrates that verbal, psychological, and emotional abuse are often missed by healthcare providers or not given adequate attention (Atmaca \& Gençöz, 2016; Gay, Harding, Jackson, Burns, \& Baker, 2013; Widom, Czaja, \& Dutton, 2014).

Women in the study consistently reported a desire for more mental health providers with specialized knowledge of dissociative disorders and DID. Early access to expert care was a chief concern among participants. Participants consistently felt that earlier recognition and treatment of DID would have improved their chances of avoiding or escaping IPV. As discussed in Chapter Two, nurse-midwives are just one group that could play a pivotal role in early detection and appropriate coordination of care. Peer support was another suggestion that participants recommended to improve care of women with DID who experience IPV. Improving nurses' access to trauma-specific training would allow them to facilitate group therapy interventions. Due to negative experiences in shelters, participants recommended the creation of a temporary residential facility specifically for women with dissociative disorders staffed by trauma-informed nurses and providers, as well. 


\section{Opportunities for Future Research}

As discussed previously, additional research with a more diverse sample is warranted. Other qualitative approaches, such as phenomenology and narrative analysis, would contribute more robust data about the experiences of women with DID who experience IPV. Additionally, it may be beneficial to replicate the study with a population of men with DID who experience IPV. Although this is an even smaller and more difficult population to access, the literature demonstrates that male survivors of child maltreatment do experience IPV (Loeb et al., 2014), and it is feasible that they may cope differently. It is more difficult to detect both IPV and DID in a male population, so healthcare providers would need additional training and support on how to screen and assess these individuals (Loeb et al., 2014).

Additional quantitative research with this vulnerable population would be a valuable addition to what is currently a very limited body of knowledge. Specifically, statistical information about the number and frequency of IPV resources utilized by women with DID, as well as their level of satisfaction and perception of the outcomes, would assist providers in tailoring interventions to the specific needs of this population. Experimental intervention studies to test the efficacy of various group therapies, individual therapy, and educational interventions would bolster nurses' ability to plan and implement specialized care to women with DID who experience IPV. Due to challenges in accessing this vulnerable population, online and other distance-mediated experimental interventions may lead to the creation of programs that would increase access to care and begin to address the shortage of healthcare providers specializing in the treatment of 
dissociative disorders. The development and testing of standardized assessment tools specific to individuals with DID who experience IPV should be pursued, as well.

Participants in the study described in Chapter Four consistently observed that nurses and other healthcare providers would benefit from additional education on dissociative disorders and IPV. Similarly, QSR findings reported in Chapter Three illuminate the importance for the healthcare provider to create a safe atmosphere to discuss abuse with patients. Chapter Two discusses educational deficits within the nursemidwife population, as well as a desire for additional training to work with survivors. Future research directions might include the creation and distribution of an electronic survey to compile detailed information about the education and training of nurses in this area. Surveys could be distributed to schools of nursing or practicing nurses, both nationally and internationally, to collect data about the quality, amount, and type (e.g., theory and/or clinical) of education and training provided on dissociative disorders and IPV at all educational levels (baccalaureate, masters, and doctoral). These data may inform strategies to improve training of nurses and other healthcare professionals in this area.

Although it was beyond the scope of this qualitative inquiry, some participants reported aggression or abuse towards their abusive partners. Chapter Two acknowledges the link between CM and perpetration of IPV, but that phenomenon is not included in the scope of the review. Further qualitative and quantitative studies may add additional insight into the experiences of women with DID who are perpetrators of IPV, as the literature demonstrates that complex trauma may be a significant factor (Flemke \& Underwood, 2014). Additionally, two participants discussed the importance of service 
dogs, in terms of sources of support and positive coping mechanisms. Although the benefit of service animals is widely known and often studied, particularly in veteran populations (Krause-Parello, Sarni, \& Padden, 2016), additional research on the perceived benefit of a supportive service animal would improve knowledge and potentially offer an additional coping resource for women with DID who experience IPV.

Overall, the women interviewed for the study described in Chapter Four expressed a desire to "give back" by participating and sharing their experiences. They acknowledged wanting to help other women like themselves get earlier and more specialized care. This is consistent with findings from the QSR in Chapter Three, indicating that women appreciate being asked about their abuse experiences and participating in research (Snyder, 2016). Going forward, researchers should strive to reach vulnerable populations that are at risk for abuse and endeavor to include them in future studies. 


\section{References}

Abernethy, A.P., Capell, W.H., Aziz, N.M., Ritchie, C., Prince-Paul, M., Bennett, R.E.,...Kutner, J.S. (2014). Ethical conduct of palliative care research: Enhancing communication between investigators and institutional review boards. Journal of Pain and Symptom Management, 48, 1211-1221.

Arias, B.J., \& Johnson, C.V. (2013). Voices of healing and recovery from childhood sexual abuse. Journal of Child Sexual Abuse, 22, 822-841. doi: $10.1080 / 10538712.2013 .830669$

Atmaca, S., \& Gençöz, T. (2016). Exploring revicitimization process among Turkish women: The role of early maladaptive schemas on the link between child abuse and partner violence. Child Abuse \& Neglect, 19, 219-232.

Black, M.C., Basile, K.C., Breiding, M.J., Smith, S.G., Walters, M.L., Merrick, M.T., Chen, J., \& Stevens, M.R. (2011). The national intimate partner and sexual violence survey (NISVS): 2010 summary report. Atlanta, GA: National Center for Injury Prevention and Control, Centers for Disease Control and Prevention.

Bradbury-Jones, C., Taylor, J., Kroll, T., \& Duncan, F. (2014). Domestic abuse awareness and recognition among primary healthcare professionals and abused women: A qualitative investigation. Journal of Clinical Nursing, 23, 3057-3068. doi: 10.1111/jocn.12534 
Brand, B.L., Classen C., Lanius, R., Loewenstein, R., McNary, S., Pain, C., \& Putnam, F. (2009). A naturalistic study of dissociative identity disorder and dissociative disorder not otherwise specified patients treated by community clinicians. Psychological Trauma: Theory, Research, Practice, \& Policy, 12(2), 153-171. http://dx.doi.org/10.1037/a0016210

Collins, C.M., O’Neill-Arana, M.R., Fontes, L.A., \& Ossege, J.M. (2014). Catholicism and childhood sexual abuse: Women's coping and psychotherapy. Journal of Child Sexual Abuse, 23, 519-537. doi: 10.1080/10538712.2014.918071

Dean, J., Wollin, J., Stewart, D., Debattista, J., \& Mitchell, M. (2012). Hidden yet visible: Methodological challenges researching sexual health in Sudanese refugee communities. Culture, Health \& Sexualtiy, 14, 911-924.

Engstrom, M., El-Bassel, N., \& Gilbert, L. (2012). Childhood sexual abuse characterisitics, intimate partner violence exposure, and psychological distress among women in methadone treatment. Journal of Substance Abuse Treatment, 43, 336-376.

Flemke, K., \& Underwood, J. (2014). Childhood abuse and women's use of intimate partner violence: Exploring the role of complex trauma. Partner Abuse, 5, 98-112.

Freyd, J.J. (1994). Betrayal trauma: Traumatic amnesia as an adaptive response to childhood abuse. Ethics \& Behavior, 4, 307-329.

Gay, L.E., Harding, H.G., Jackson, J.L., Burns, E.E., \& Baker, B.D. (2013). Attachment style and early maladaptive schemas as mediators of the relationship between childhood emotional abuse and intimate partner violence. Journal of Aggression, Maltreatment, \& Trauma, 22, 408-424. 
Harper, K., Stalker, C.A., Palmer, S., \& Gadbois, S. (2008). Adults traumatized by child abuse: What survivors need from community-based mental health professionals. Journal of Mental Health, 17, 361-374. doi: 10.1080/09638230701498366

Koeppel, M.D.H., \& Bouffard, L. (2014). Sexual orientation, child abuse, and intimate partner violence victimization. Violence Victims, 29, 436-450.

Krause-Parello, C.A., Sarni, S., \& Padden, E. (2016). Military veterans and canine assistance for post-traumatic stress disorder: A narrative review of the literature. Nurse Education Today, 47, 43-50. http://dx.doi.org.proxytu.researchport.umd.edu/10.1016/j.nedt.2016.04.020

Loeb, T.B., Holloway, I.W., Galvan, F.H., Wyatt, G.E., Myers, H.F., Glover, D.A.,...Liu, H. (2014). Associations between intimate partner violence and posttraumatic stress symptom severity in a multiethnic sample of men with histories of childhood sexual abuse. Violence \& Victims, 29, 451-463.

Loewenstein, R., \& Wait, S. (2008). The trauma disorders unit. In Textbook of Hospital Psychiatry (pp. 103-118). Washington, D.C.: American Psychiatric Publishing.

Matthew, L., \& Barron, I.G. (2015). Participatory action research on help-seeking behaviors of self-defined ritual abuse survivors: A brief report. Journal of Child Sexual Abuse, 24, 429-433. doi: 10.1080/10538712.2015.1029104

Mkandawire-Valhmu, L., Rice, E., \& Bathum, M.E. (2009). Promoting an egalitarian approach to research with vulnerable populations of women. Journal of Advanced Nursing, 65, 1725-1734. doi: 10.1111/j.1365-2648.2009.05045.x

Parker, B., \& Ulrich, Y. (1990). A protocol of safety: Research on abuse of women. Nursing Research, 39, 248-250. 
Riden, H.E., Grooms, K.N., Clark, C.R., Cohen, L.R., Gagne, J., Tovar, D.A.,...Johnson, P.A. (2012). Lessons learned obtaining informed consent in research with vulnerable populations in community health center settings. BMC Research Notes, 5, 624-636.

Snyder, B.L. (2016). Women's experience of being interviewed about abuse: A qualitative systematic review. Journal of Psychiatric and Mental Health Nursing. 23, 605-613. doi: 10.1111/jpm. 12353

Webermann, A.R., Brand, B.L., \& Chasson, G.S. (2014). Childhood maltreatment and intimate partner violence in dissociative disorder patients. European Journal of Psychotraumatology, 5, 1-8. http://dx.doi.org/10.3402/ejpt.v5.24568

Widom, C.S., Czaja, S., \& Dutton, M.A. (2014). Child abuse and neglect and intimate partner violence victimization and perpetration: A prospective investigation. Child Abuse \& Neglect, 38, 650-663. 


\section{Appendix}

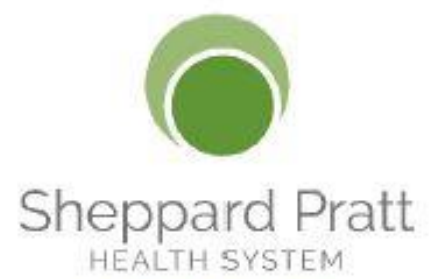

We help. You heal.

DATE:

TO:

FROM:

PROJECT TITLE:

SUBMISSION TYPE:

ACTION:

APPROVAL DATE:

EXPIRATION DATE:

REVIEW TYPE:

April 20, 2015

Briana Snyder, MSN, RN-BC

Sheppard Pratt IRB

[633204-3] Views of Women with Dissociative Identity Disorder on Intimate Partner Violence

Revision

APPROVED

April 20, 2015

April 20, 2016

Expedited Review

Thank you for your submission of Revision materials for this project. The Sheppard Pratt IRB has APPROVED your submission based on applicable federal regulations. This approval is based on an appropriate risk/benefit ratio and a project design wherein the risks have been minimized. All research must be conducted in accordance with this approved submission. Please note that any future revision to approved materials must be approved by this committee prior to initiation. Please use the appropriate revision forms for this procedure.

Please remember that informed consent is a process beginning with a description of the project and insurance of participant understanding followed by a signed consent form. Informed consent must continue throughout the project via dialogue between the researcher and research participation. Federal regulations require each participant to receive a copy of the signed consent document.

AII UNANTICIPATED PROBLEMS involving risks to subjects or others and SERIOUS and UNEXPECTED adverse events must be reported promptly to this committee. Please use the appropriate reporting forms for this procedure.

AII NON-COMPLIANCE issues or COMPLAINTS regarding this project at Sheppard Pratt sites must be reported promptly to this office. Please use the appropriate reporting forms for this procedure.

This project has been determined to be a Minimal Risk project. Based on the risks, this project requires continuing review by this committee by April 20,2016 . Please use the appropriate forms for this procedure. Your documentation for continuing review must be received with sufficient time for review and continued approval before the expiration date of April 20, 2016. 
Please note that all research records must be retained for a minimum of three years after the completion of the project.

If you have any questions, please contact Gayle Hurt at ghurt@sheppardpratt.org. Please include your project title in all correspondence with this committee.

This letter has been electronically signed in accordance with all applicable regulations, and a copy is retained within Sheppard Pratt IRB's records. 


\title{
University of Missouri IRB Authorization Agreement
}

Institution A: IRB Providing Review

Name: Sheppard Pratt Health System

Address: 6501 North Charles Street, Towson, MD 21204

IRB Registration Number: 00004510

FWA Number: 00008047

\author{
Institution B: Relving on the Designated IRB \\ Name: University of Missouri-Columbia \\ Address: 190 Galena, DC074, Columbia MO 65211 \\ IRB Registration Number: 00000731 \\ FWA Number: 00002876
}

The Officials signing below agree that Institution $B$ may rely on the designated IRB (Institution A) for review and continuing oversight of its human subject research described below:

This agreement is limited to the following specific research project(s):

Title of Research Project: Views of Women with Dissociative Identity Disorder on Intimate Partner Violence

Name of Principal Investigator: Briana Snyder

IRB Project Number: 633204-3

Institution A: The review performed will meet the human subject's protection requirements of Institution/B's OHRPapproved FWA. The IRB will follow written procedures for reporting its findings and actions to appropriate officials at Institution $B$. Relevant minutes of IRB meetings will be made available to Institution $B$ upon request.

Institution B: Ensure compliance with the IRB's determinations and with the terms of its OHRP-approved Assurance.

Additional terms and responsibilities outlined on the attached addendum are agreed upon by all parties and attested to by signature below:

Signature of Signatory Official (Institution A):

Datei。

Print Full Name; Institution Title:

Phone Number; E-Mail Addregs:

Signature of Signatory Official (Institution B): Wichele Kennett Date: April 28, 2015

Print Full Name: Michele R. Kennett Institution Title: Assistant Vice Chancellor for Research

Phone Number: 573-882-3182

E-Mail Address: kennettmr@misgouri.edu 
VITA

Briana L. Snyder was born and raised in Baltimore, Maryland. She is an only child, a lifelong athlete, and a dedicated Baltimore sports fan. She completed a baccalaureate degree in ancient and medieval history in Chapel Hill, North Carolina, and developed a fanatical love of Tar Heel basketball. She moved back to Baltimore to obtain her baccalaureate and master's degrees in nursing and embarked upon her career as a psychiatric-mental health nurse working with adult survivors of severe child abuse and neglect. She quickly developed a passion for working with this underserved population and made the decision to pursue a doctoral degree at Mizzou to begin a career in research and advocacy.

Briana has always loved teaching and is currently a nurse educator at Towson University in Maryland. She resides in Baltimore with her husband, two children, and two dogs. She enjoys running marathons, practicing yoga, being outdoors with her family, and watching just about any sport. 